\title{
Clonally expanded $\gamma \delta$ T cells protect against Staphylococcus aureus skin reinfection
}

Carly A. Dillen, ${ }^{1}$ Bret L. Pinsker, ${ }^{1}$ Alina I. Marusina, ${ }^{2}$ Alexander A. Merleev, ${ }^{2}$ Orly N. Farber, ${ }^{3}$ Haiyun Liu, ${ }^{1}$ Nathan K. Archer, ${ }^{1}$ Da B. Lee, ${ }^{1}$ Yu Wang, ${ }^{1}$ Roger V. Ortines, ${ }^{1}$ Steven K. Lee, ${ }^{1}$ Mark C. Marchitto, ${ }^{1}$ Shuting S. Cai, ${ }^{1}$ Alyssa C. Ashbaugh, ${ }^{1}$ Larissa S. May, ${ }^{4}$ Steven M. Holland, ${ }^{5}$ Alexandra F. Freeman, ${ }^{5}$ Loren G. Miller, ${ }^{6}$ Michael R. Yeaman, ${ }^{6,7,8,9}$ Scott I. Simon, ${ }^{10}$ Joshua D. Milner, ${ }^{3}$ Emanual Maverakis, ${ }^{2}$ and Lloyd S. Miller,11,12,13

'Department of Dermatology, Johns Hopkins University School of Medicine, Baltimore, Maryland, USA. 2Department of Dermatology, School of Medicine, UCD, Sacramento, California, USA. ${ }^{3}$ Laboratory of Allergic Diseases, National Institute of Allergy and Infectious Diseases, NIH, Bethesda, Maryland, USA. ${ }^{4}$ Department of Emergency Medicine, School of Medicine, UCD, Sacramento, California, USA. ${ }^{5}$ Laboratory of Clinical Immunology and Microbiology, National Institute of Allergy and Infectious Diseases, NIH, Bethesda, Maryland, USA. ${ }^{6}$ Division of Infectious Diseases, ${ }^{7}$ Division of Molecular Medicine, and ${ }^{8}$ St. John's Cardiovascular Research Center, Los Angeles Biomedical Research Institute, Harbor-UCLA Medical Center, Torrance, California, USA. ${ }^{9}$ Department of Medicine, David Geffen School of Medicine at UCLA, Los Angeles, California, USA. ${ }^{10}$ Department of Biomedical Engineering, UCD, Davis, California, USA. "Department of Medicine, Division of Infectious Diseases, and 'Department of Orthopaedic Surgery, Johns Hopkins University School of Medicine, Baltimore, Maryland, USA. ${ }^{3}$ Department of Materials Science and Engineering, Johns Hopkins University, Baltimore, Maryland, USA.

\begin{abstract}
The mechanisms that mediate durable protection against Staphylococcus aureus skin reinfections are unclear, as recurrences are common despite high antibody titers and memory T cells. Here, we developed a mouse model of

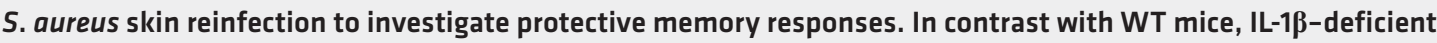
mice exhibited poor neutrophil recruitment and bacterial clearance during primary infection that was rescued during secondary S. aureus challenge. The $\gamma \delta$ T cells from skin-draining LNs utilized compensatory T cell-intrinsic TLR2/ MyD88 signaling to mediate rescue by trafficking and producing TNF and IFN- $\gamma$, which restored neutrophil recruitment and promoted bacterial clearance. RNA-sequencing (RNA-seq) of the LNs revealed a clonotypic S. aureus-induced $\gamma \delta$ $\mathrm{T}$ cell expansion with a complementarity-determining region 3 (CDR3) aa sequence identical to that of invariant $\mathrm{V} 5^{+}$ dendritic epidermal T cells. However, this T cell receptor $\gamma(T R C)$ aa sequence of the dominant CDR3 sequence was generated from multiple gene rearrangements of TRGV5 and TRGV6, indicating clonotypic expansion. TNF- and IFN- $\gamma$ producing $\gamma \delta$ T cells were also expanded in peripheral blood of IRAK4-deficient humans no longer predisposed to $S$. aureus skin infections. Thus, clonally expanded $\gamma \delta$ T cells represent a mechanism for long-lasting immunity against recurrent $S$. aureus skin infections.
\end{abstract}

\section{Introduction}

Staphylococcus aureus is a Gram-positive bacterium that is the most common cause of skin infections in humans and is also an important cause of invasive and life-threatening infections, such as pneumonia, osteomyelitis, and bacteremia (1). The precise immune responses that protect against $S$. aureus skin infections are unclear, as nearly half of individuals with an $S$. aureus skin infection suffer a recurrence (2), despite the generation of high titers of specific antibodies and memory $\mathrm{CD} 4^{+} \mathrm{T}$ cells $(3,4)$. Moreover, all prior $S$. aureus vaccines in humans that targeted antibody-mediated phagocytosis have lacked efficacy or resulted in increased mortality (5). Therefore, a greater understanding of the adaptive immune

Conflict of interest: L.S. Miller reports grant support from Medlmmune, Regeneron Pharmaceuticals, Moderna Therapeutics, and Pfizer, which are developing therapeutics and vaccines against Staphylococcus aureus and other pathogens. M.R. Yeaman is a shareholder of NovaDigm Therapeutics, which is developing new vaccines, including NDV3 targeting S. aureus and other pathogens.

Submitted: July 24, 2017; Accepted: December 19, 2017

Reference information: J Clin Invest. 2018;128(3):1026-1042.

https://doi.org/10.1172/JCI96481 responses that mediate long-lasting protection is needed to guide the future development of a successful S. aureus vaccine.

Neutrophils play an important role in host defense against $S$. aureus infections, as individuals with neutropenia (e.g., severe congenital neutropenia or as a result of chemotherapy) or impaired neutrophil function (e.g., chronic granulomatous disease) have a global susceptibility to $S$. aureus infections (6). However, certain primary immunodeficiency disorders have more selective impairment against $S$. aureus infections in the skin, including those in humans with defective IL-1R/TLR signaling (e.g., IRAK4 or MyD88 deficiency with impaired neutrophil recruitment; ref. 7-9) and in humans deficient in Th17 cells or IL-17 responses (i.e., autosomal dominant hyper-IgE syndrome and IL-17F or IL-17Ra deficiency; ref.10-12). Similarly, MyD88-deficient mice have impaired neutrophil recruitment and host defense against $S$. aureus skin infections, predominantly due to loss of IL-1 $\beta / \mathrm{IL}-1 \mathrm{R} 1 /$ MyD88 signaling (13, 14) and subsequent T cell-mediated IL-17 responses (15-18).

Nevertheless, the responses that mediate durable immunity against recurrent $S$. aureus skin infections likely involve mechanisms beyond MyD88/IRAK4 signaling and Th17/IL-17 responses because the childhood susceptibility to $S$. aureus skin infections in 
A

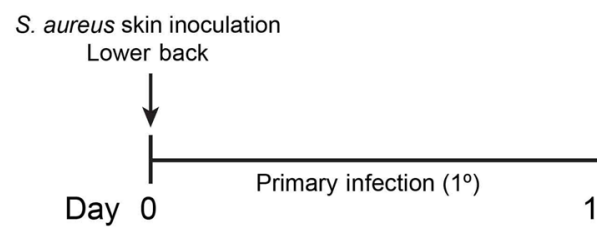

B

Representative photographs
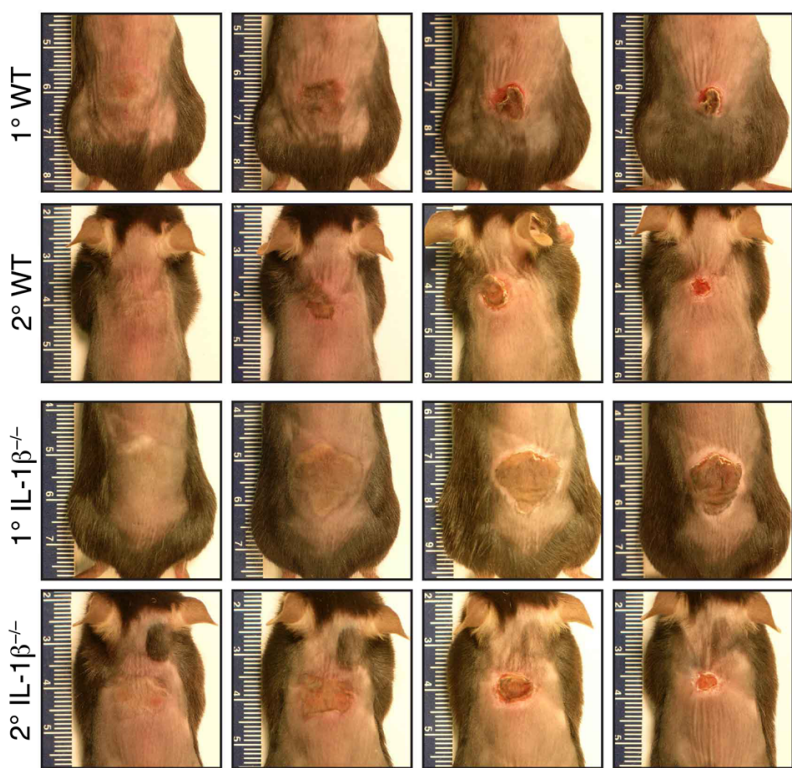

$1^{\circ} \rightarrow \quad 1$

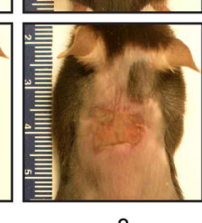

Days

C Total lesion size $\left(\mathrm{cm}^{2}\right)$

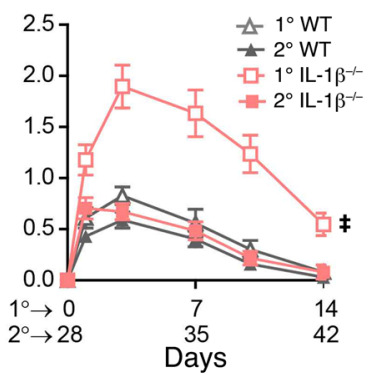

G Total lesion size $\left(\mathrm{cm}^{2}\right)$
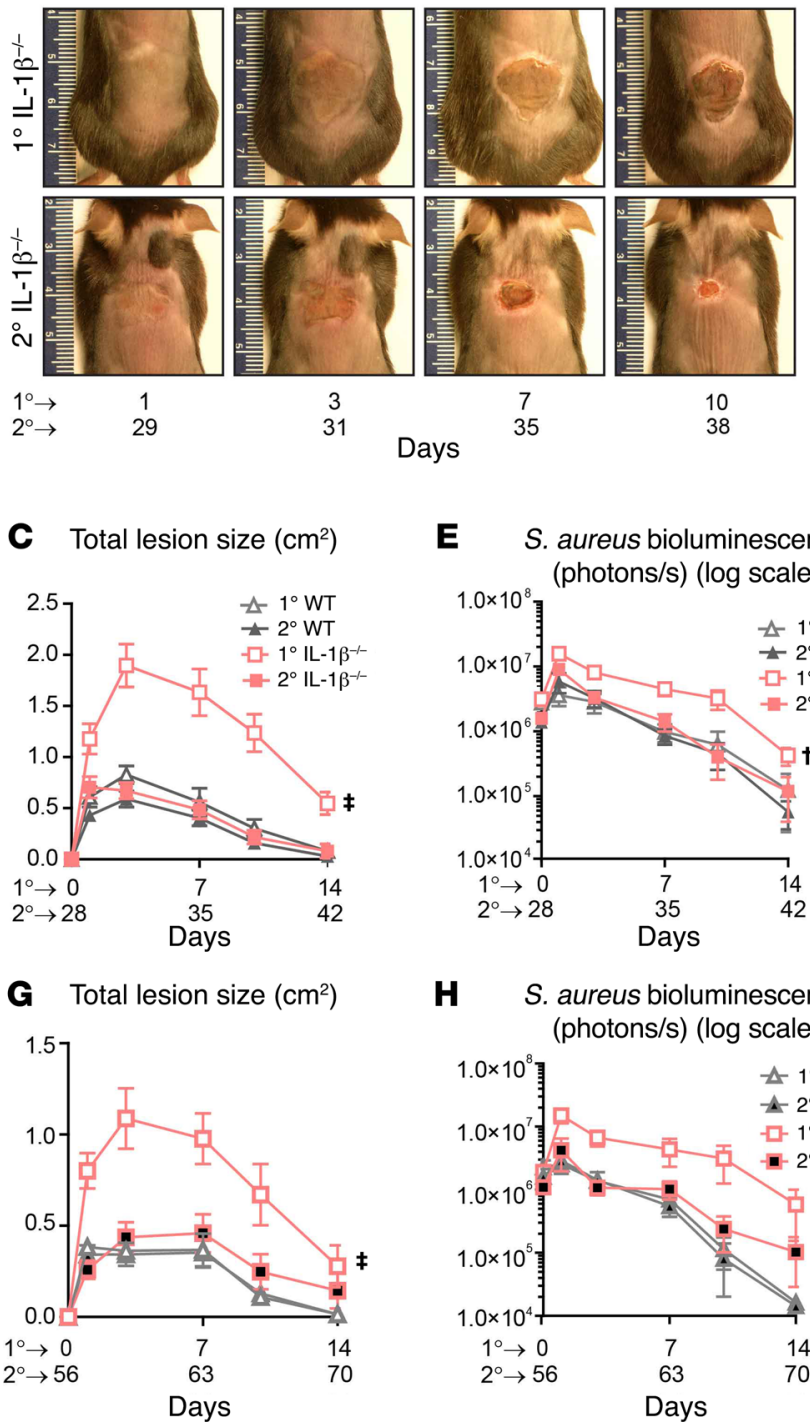

E S. aureus bioluminescence (photons/s) (log scale)

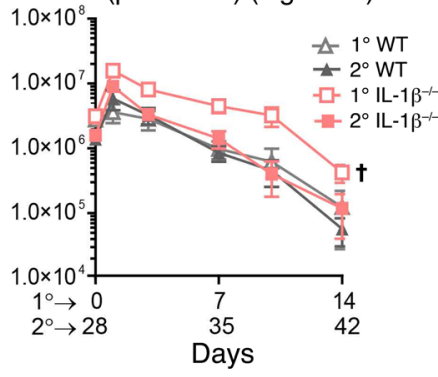

H S. aureus bioluminescence (photons/s) (log scale)

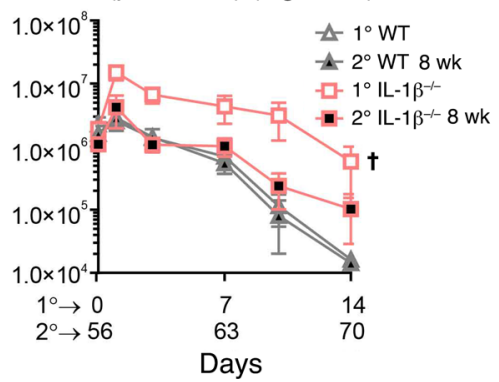

S. aureus skin inoculation Upper back

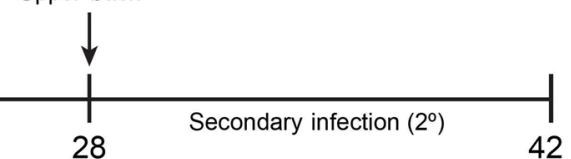
42
D

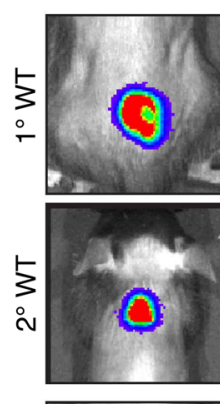

S. aureus bioluminescence (color scale)
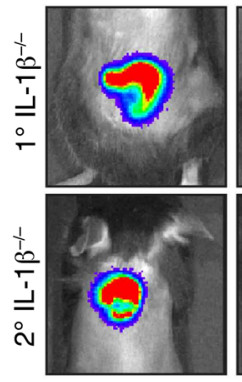

$\begin{array}{lc}1^{\circ} \rightarrow & 1 \\ 2^{\circ} \rightarrow & 29\end{array}$
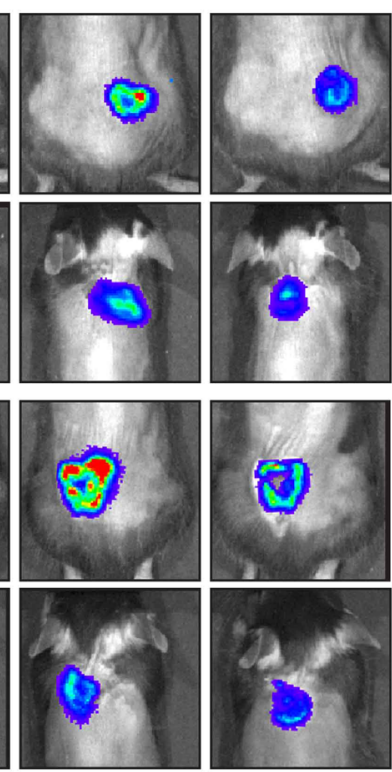

7
35
Days

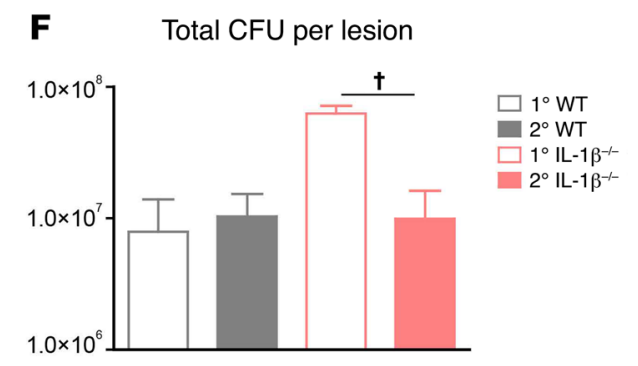

I Total lesion size $\left(\mathrm{cm}^{2}\right)$

J $S$. aureus bioluminescence

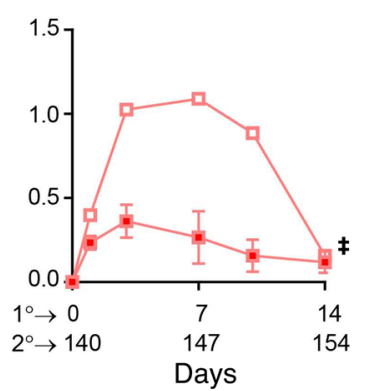

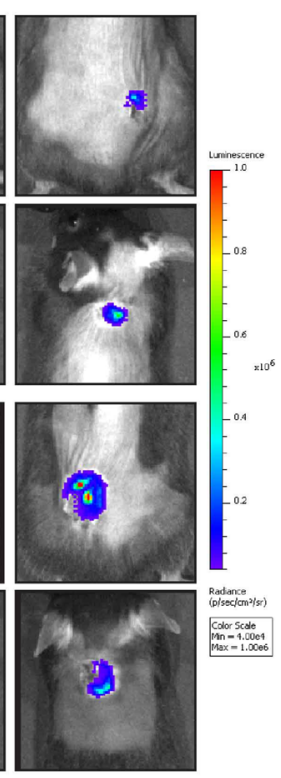

10
38

Figure 1. IL-1/ $\boldsymbol{\beta}^{-/-}$mice are protected against an S. aureus skin reinfection. (A) Time line for S. aureus skin reinfection model. (B) Representative photographs of skin lesions. (C) Mean total lesion size $\left(\mathrm{cm}^{2}\right) \pm$ SEM $(n=10 /$ group). (D) Representative S. aureus in vivo bioluminescent signals. (E) Mean total flux (photons/s) \pm SEM ( $n=10 /$ group). (F) Ex vivo CFUs from d7 infected skin ( $n=5 /$ group). (G-J) Mean total lesion size ( $\left(\mathrm{cm}^{2}\right) \pm$ SEM and mean total flux (photons $/ \mathrm{s}) \pm$ SEM after 8 -week (G and $\mathbf{H}$ ) or 20 -week (I and J) convalescent period $\left(n=5\right.$-10/group). ${ }^{\dagger} P<0.01,{ }^{\ddagger} P<0.001$, compared with $1^{\circ}$ mice, as calculated by 2-way ANOVA (C, E, G-J) or 2-tailed Student's $t$ test (F). Results in B-E and $\mathbf{G}$ and $\mathbf{H}$ are a compilation of 2 independent experiments. Results in $\mathbf{F}$ are representative of 2 independent experiments. 


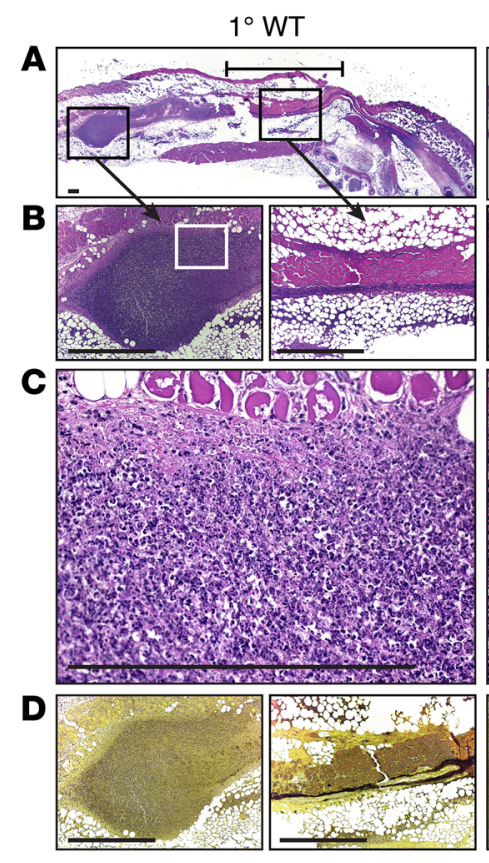

E

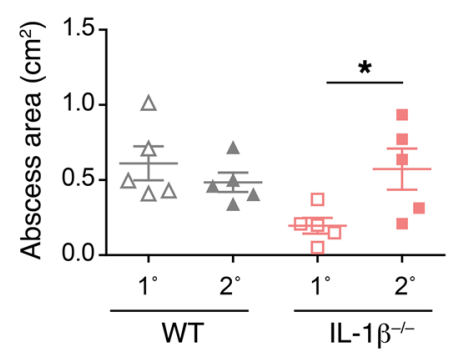

$2^{\circ} \mathrm{WT}$
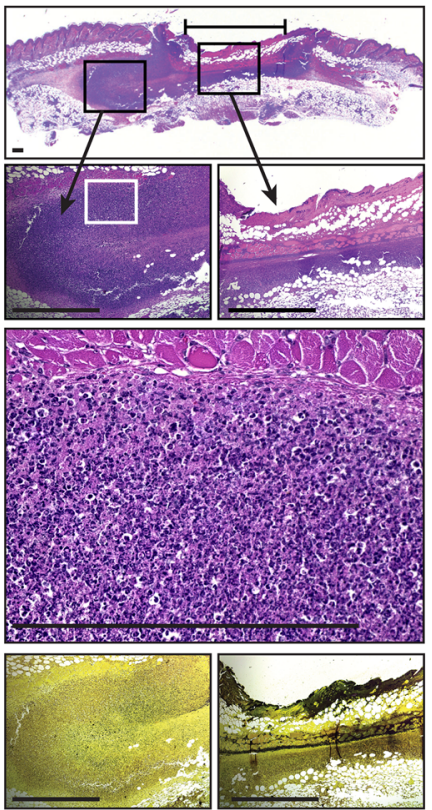

$\mathbf{F}$

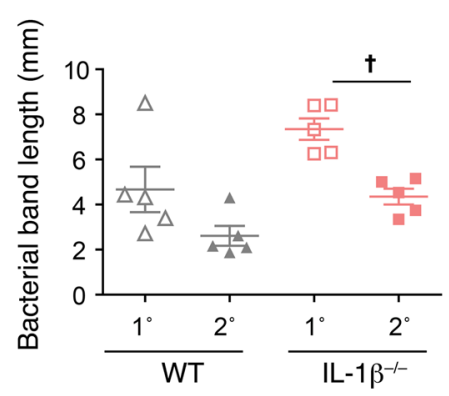

$1^{\circ} \mathrm{IL}-1 \beta^{-1-}$
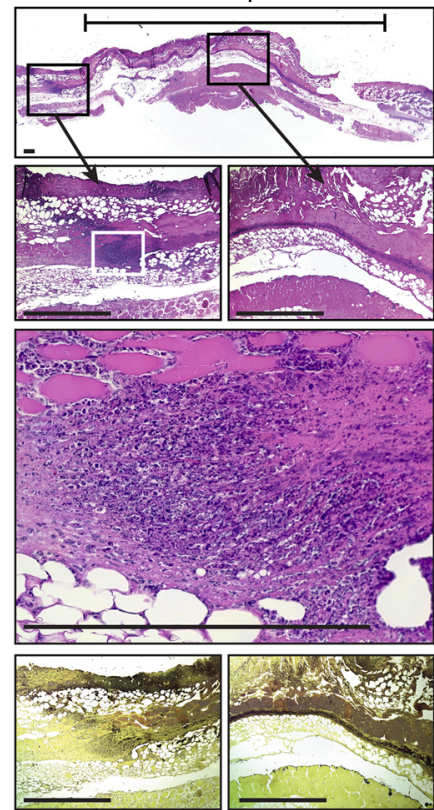

$G$

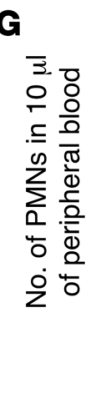

$2^{\circ} \mathrm{IL}-1 \beta^{-1-}$
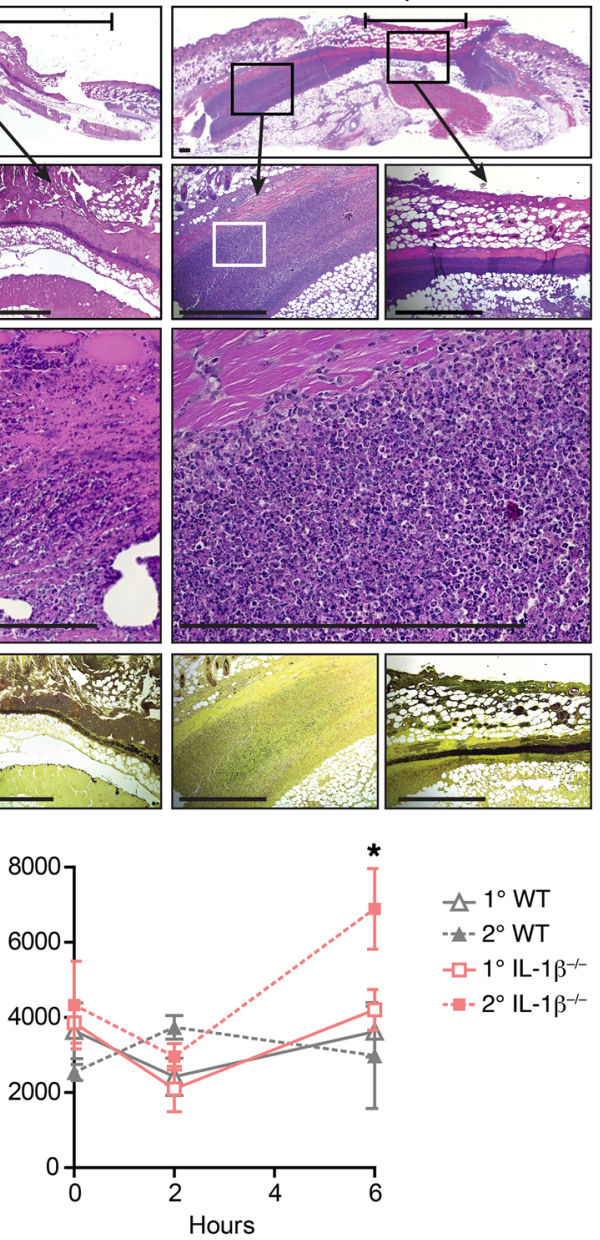

Figure 2. Neutrophil recruitment is restored in IL-1/ ${ }^{-/-}$mice during secondary infection. (A-D) Representative H\&E- (A-C) and Gram-stained (D) histologic sections at 3 days after $\mathbf{S}$. aureus inoculation. Scale bars: $240 \mu \mathrm{m}$. B and $\mathbf{D}$ show higher magnification of the black boxed area in $\mathbf{A}$. C shows higher magnification of the white boxed area in $\mathbf{B}(n=5 / \mathrm{group})$. (E) Mean abscess area $\left(\mathrm{cm}^{2}\right) \pm \mathrm{SEM}$ and $(\mathbf{F})$ mean bacterial band width ( $\left.\mathrm{mm}\right) \pm S E M$ from histologic sections ( $n=5$ /group). (G) Mean neutrophil (PMN) number per $10 \mu$ lof blood \pm SEM from 0 to 6 hours after $S$. aureus inoculation $(n=5 / g r o u p)$. ${ }^{*} P<0.05$; ${ }^{\dagger} P<0.01$, compared with $1^{\circ}$ mice, as calculated by 2 -tailed Student's $t$ test (E-G). Results in $\mathbf{G}$ are representative of 2 independent experiments.

humans with MyD88 or IRAK4 deficiency wanes in adulthood (19) and humans with genetic defects in IL-17 responses suffer from mucocutaneous candidiasis more commonly than $S$. aureus skin infections (20). Therefore, we set out to identify these concomitant protective immune responses that develop following a primary $S$. aureus skin infection that provide long-lasting protection against a secondary challenge.

\section{Results}

Protection of IL-1 $\beta$-deficient mice against $S$. aureus skin reinfection. To assess whether immune protection developed following an $S$. aureus skin infection, WT C57BL/6 mice underwent a primary $S$. aureus skin infection $\left(1^{\circ}\right)$ in the lower back followed by a secondary $S$. aureus skin infection $\left(2^{\circ}\right)$ in a distant uninvolved site on the upper back on day 28 (d28) (Figure 1A). Both $1^{\circ}$ and $2^{\circ}$ WT mice developed skin lesion sizes (Figure 1, B and C) and bacterial burdens (measured by in vivo bioluminescence imaging and ex vivo CFU counting) (Figure 1, D-F) that did not significantly differ from each other, similarly to what occurred in prior reports $(17,18,21)$. Given these results, we hypothe- sized that the normal activity of IL-1 $\beta$ in WT mice resulted in an effective response during both the $1^{\circ}$ and $2^{\circ}$ infections, making it difficult to observe an additional effect of any adaptive immune responses that developed. Therefore, we evaluated the $1^{\circ}$ and $2^{\circ} S$. aureus skin infections in IL-1 $\beta^{-/-}$mice, which have impaired neutrophil recruitment and host defense during a $1^{\circ}$ S. aureus skin infection (13). The $1^{\circ}$ $\mathrm{IL}_{-1} \beta^{-/-}$mice developed markedly larger lesions and increased bacterial burden compared with WT mice (Figure 1, B-F). In contrast, $2^{\circ} \mathrm{IL}-1 \beta^{-/-}$mice were protected and their responses were similar to those of WT mice. The protection was long term and not limited to a specific skin location, since $2^{\circ} \mathrm{IL}-1 \beta^{-/-}$mice were still protected when the convalescent interval was increased to 8 or 20 weeks (Figure 1, $\mathrm{G}^{-} \mathrm{J}$ ) or when the locations for $1^{\circ}$ and $2^{\circ}$ inoculations were reversed (Supplemental Figure 1, A and B; supplemental material available online with this article; https://doi.org/10.1172/JCI96481DS1).

Neutrophil recruitment in reinfected IL-1 $\beta$-deficient mice. By histology, $1^{\circ}$ and $2^{\circ}$ WT mice developed neutrophil abscesses at the peripheral edges and a dense band of Gram-positive $S$. aureus bacteria in the center (Figure $2, \mathrm{~A}-\mathrm{F}$ ). $1^{\circ} \mathrm{IL}-1 \beta^{-/-}$mice had defective neutro- 
A Total serum $\lg \mathrm{G}(\mathrm{pg} / \mathrm{ml})$
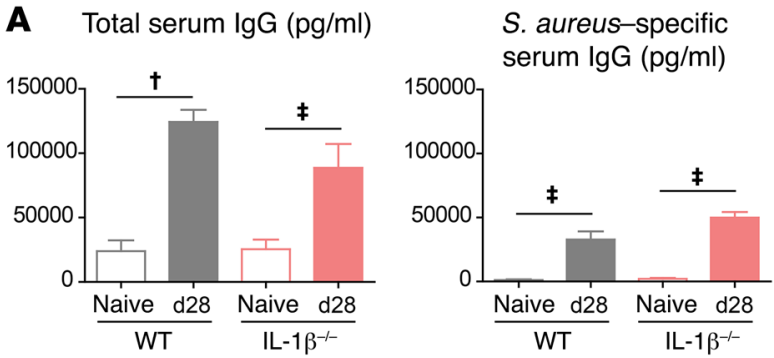

C

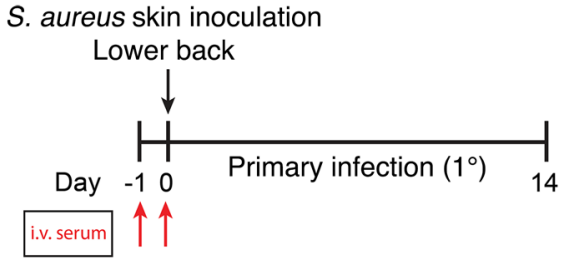

B Total skin $\lg G(\mathrm{pg} / \mathrm{mg})$

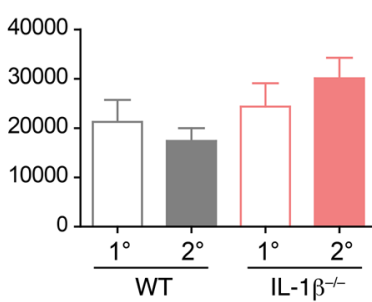

D Total lesion size $\left(\mathrm{cm}^{2}\right)$

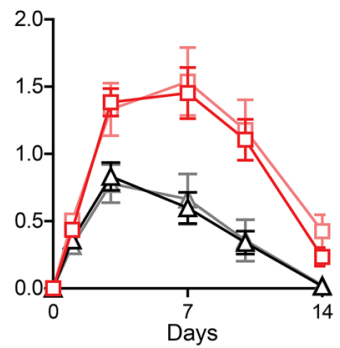

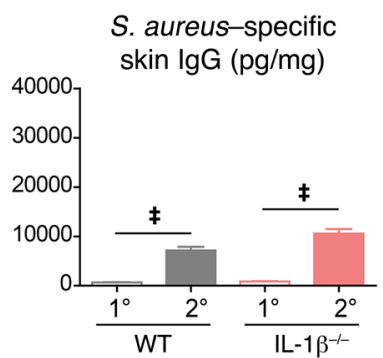

S. aureus bioluminescence

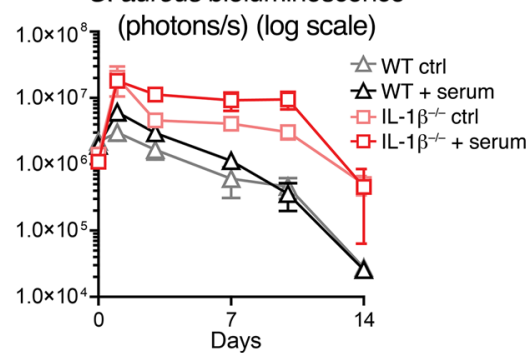

Figure 3. Specific antibodies are not involved in protective immunity. (A) Mean total and S. aureus-specific serum IgG (pg/ml) $\pm \mathrm{SEM}$ at d28 $(n=5 /$ group). (B) Mean total and S. aureus-specific IgG levels IgG ( $\mathrm{pg} / \mathrm{mg}$ tissue weight) $\pm S E M$ in skin homogenates at 1 day after $S$. aureus inoculation ( $n=5 /$ group). (C) Time line of i.v. serum transfer. (D) Mean total lesion size $\left(\mathrm{cm}^{2}\right) \pm$ SEM and mean total flux (photon/s) \pm SEM $\left(n=10 /\right.$ group). ${ }^{\dagger} P<0.01 ;{ }^{\ddagger} P<$ 0.001 , as measured by 2-tailed Student's $t$ test (A and $\mathbf{B}$ ). Results in $\mathbf{D}$ are a compilation of 2 independent experiments.

phil abscess formation with an increased band length of Gram-positive bacteria. In contrast, $2^{\circ} \mathrm{IL}-1 \beta^{-/-}$mice had restored neutrophil abscess formation with an increase in circulating neutrophils (Figure $2 \mathrm{G})$. Neutrophils differentiate into distinct effector subsets after an $S$. aureus infection (22), suggesting they might mediate trained immunity against a subsequent $S$. aureus challenge as previously described (23). To evaluate this possibility, neutrophils from $\mathrm{d} 28$ $\mathrm{IL}-1 \beta^{-/-}$mice were transferred to naive WT and IL-1 $\beta^{-/-}$mice 2 hours prior to $1^{\circ} \mathrm{S}$. aureus skin infection. However, this did not result in any protection (Supplemental Figure 2, A and B).

Role of antibodies in conferring protection. Next, we evaluated whether more conventional adaptive immune responses contributed to the protection in $2^{\circ} \mathrm{IL}-1 \beta^{-/-}$mice. $\mathrm{d} 28 \mathrm{WT}$ and IL-1 $\beta^{-/-}$mice had higher total IgG levels and $S$. aureus-specific IgG titers in the serum compared with naive mice (Figure $3 \mathrm{~A}$ ). There was also increased $S$. aureus-specific IgG in the infected skin of $2^{\circ} \mathrm{WT}$ and IL-1 $\beta^{-/-}$mice compared with naive mice (Figure 3B). To determine whether these antibodies conferred protection, serum from $\mathrm{d} 28$ $\mathrm{IL}-1 \beta^{-/-}$mice was transferred to naive WT and IL-1 $\beta^{-/-}$mice prior to $1^{\circ}$ S. aureus skin infection (Figure $3 \mathrm{C}$ ). However, this passive transfer of $S$. aureus-specific antibodies did not confer protection in $1^{\circ}$ WT or IL-1 $\beta^{-/-}$mice (Figure 3D).

Role of $T$ cells in mediating protection. To determine whether the observed protection was mediated by lymphocytes either residing in the skin or trafficking from LNs, mice were treated with FTY720, which inhibits lymphocyte efflux from LNs (24). FTY720 treatment of $2^{\circ} \mathrm{IL}-1 \beta^{-/-}$mice resulted in increased lesion sizes and bacterial burden (Figure 4, A and B) and loss of neutrophil abscess formation (Figure $4, \mathrm{C}-\mathrm{G}$ ), similarly to what occurred in $1^{\circ} \mathrm{IL}-1 \beta^{-/-}$mice. Thus, trafficking lymphocytes from draining LNs promoted the protective neutrophil recruitment response. This role for trafficking lymphocytes was only observed in $2^{\circ} \mathrm{IL}-1 \beta^{-/-}$mice, as FTY720 treatment had no effect on $2^{\circ} \mathrm{WT}$ mice. $\mathrm{LN}$ cells harvested from $\mathrm{d} 28 \mathrm{IL}-1 \beta^{-/-}$mice and transferred to naive IL-1 $\beta^{-/-}$mice prior to $1^{\circ} \mathrm{S}$. aureus skin infection also conferred protection (Figure $4, \mathrm{H}$ and I). Furthermore, the protective response was unique to $\mathrm{LN}$ cells from previously infected IL-1 $\beta^{-/-}$mice, since the transfer of $\mathrm{LN}$ cells from naive IL-1 $\beta^{-/-}$mice to naive IL-1 $\beta^{-/-}$mice had no effect (Supplemental Figure 3).

Since Th17 cells and Th1 cells have been implicated in host defense against $S$. aureus skin infections in humans (4, 10-12, 2527) and mice (15-18), a role for $C D 4^{+} \mathrm{T}$ cells was evaluated using anti-CD4 antibody depletion. Treatment successfully depleted $\mathrm{CD}^{+} \mathrm{T}$ cells from the blood and LNs (91\% and 97\%, respectively) while not significantly affecting the numbers of $\mathrm{CD} 8^{+} \mathrm{T}$ cells (Supplemental Figure 4). However, anti-CD4 antibody treatment had no effect on $2^{\circ} \mathrm{IL}-1 \beta^{-/-}$or WT mice (Figure 4 , J and $\mathrm{K}$ ), indicating that $\mathrm{CD}^{+} \mathrm{T}$ cells were not responsible for the protection observed.

$\gamma \delta \mathrm{T}$ cells from LNs mediate protection. During the innate immune response that occurs within hours of an $S$. aureus skin infection in naive WT mice, IL-1 $\beta$ induces $\gamma \delta$ T cells to promote IL-17-mediated neutrophil recruitment (16). However, whether $\gamma \delta$ $\mathrm{T}$ cells contribute to host defense against a $2^{\circ} \mathrm{S}$. aureus skin infection is unknown. To evaluate this possibility, total LN cells from d28 IL-1 $1 \beta^{-/-}$mice were depleted of non-T cells; this was followed by isolating $\gamma \delta$ T cells (TCR $\gamma \delta^{+}$cells) using magnetic bead separation. The enriched $\gamma \delta$ T cells or the "flow-through" (CD3+ lymphocytes devoid of $\gamma \delta$ T cells) (Supplemental Figure 5) was transferred to naive IL-1 $\beta^{-/-}$mice prior to $1^{\circ}$ S. aureus skin infection (Figure $5 \mathrm{~A}$ ). Remarkably, transfer of only 50,000 $\gamma \delta$ T cells mediated protection to a greater extent than 5 million other $\mathrm{CD}^{+} \mathrm{T}$ cells in the flow-through (Figure 5B). In addition, to evaluate for synergistic protection between $\gamma \delta$ and $\mathrm{CD}^{+} \mathrm{T}$ cells as reported for other bacterial infections (28), lesion sizes and in vivo bioluminescence were determined in naive $\mathrm{IL}^{-1} \beta^{-/-}$mice that received no cell trans- 

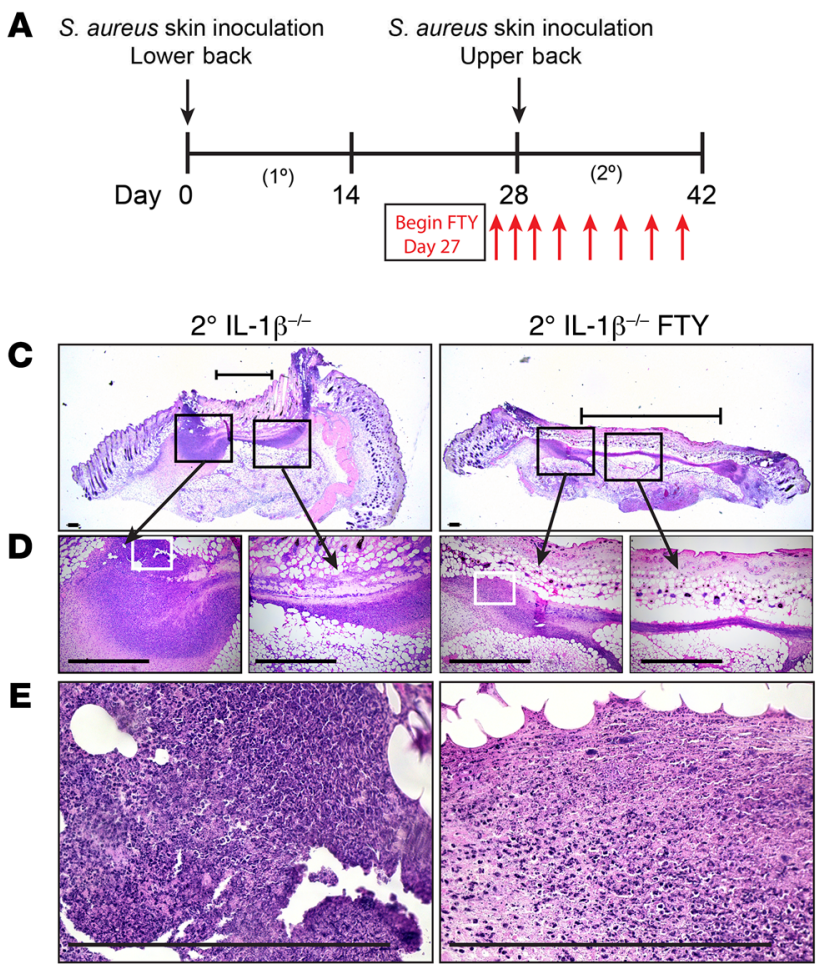

H
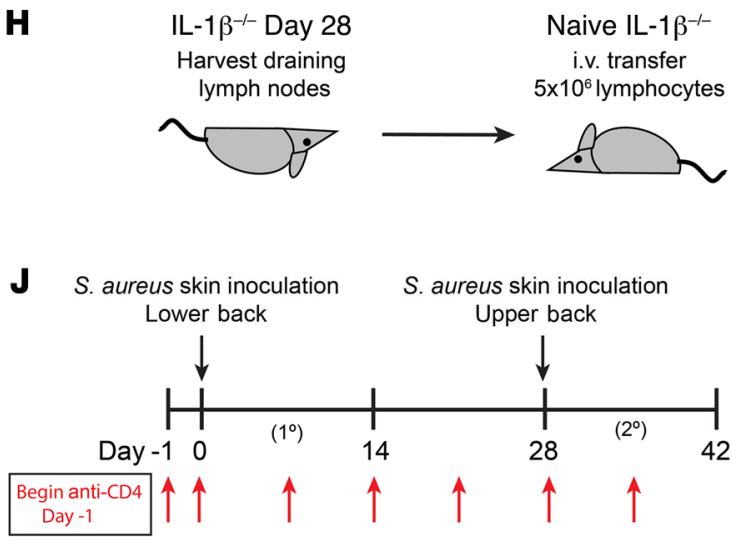

B

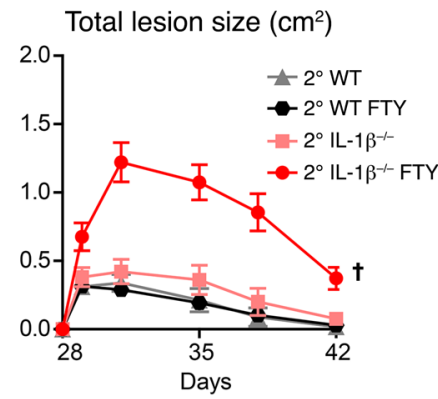

$\mathbf{F}$

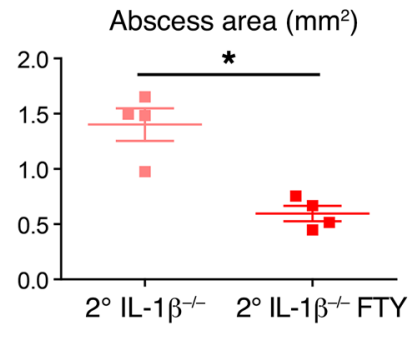

I Total lesion size $\left(\mathrm{cm}^{2}\right)$
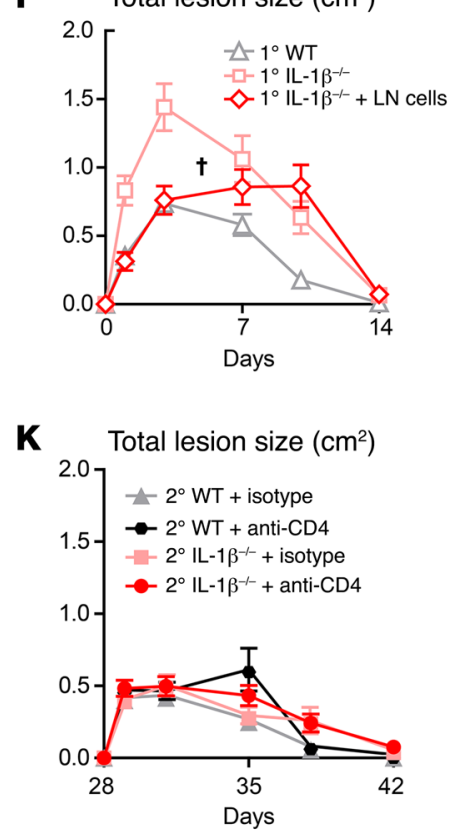

S. aureus bioluminescence

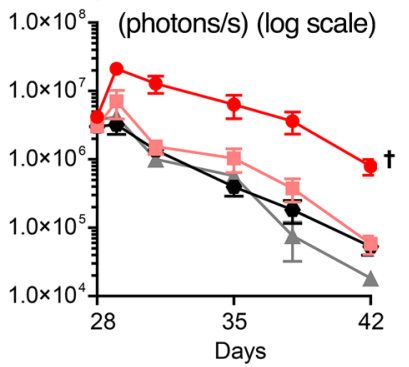

G

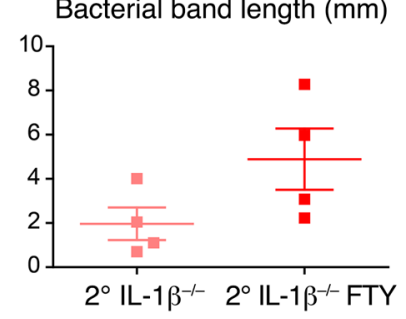

$S$. aureus bioluminescence

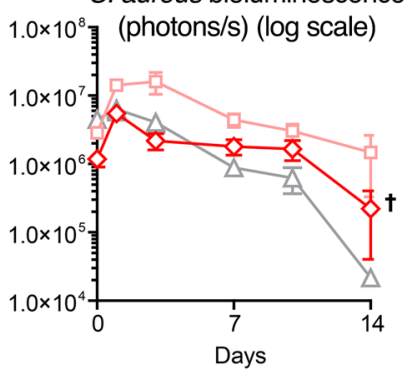

$S$. aureus bioluminescence

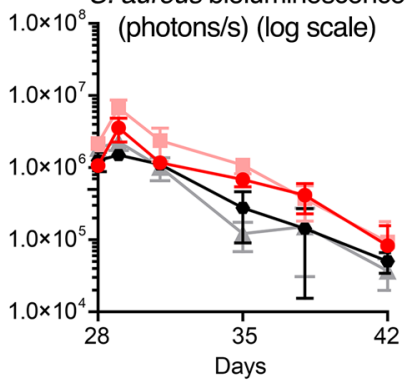

Figure 4. T cells trafficking from draining LNs mediate the protection. (A) Time line of FTY720 administration with (B) mean total lesion size ( $\left.\mathrm{cm}^{2}\right) \pm \mathrm{SEM}$ and mean total flux (photon/s) \pm SEM ( $n=10$ /group). (C) Representative H\&E-stained histologic sections at 3 days after S. aureus inoculation. Scale bars: 240 $\mu \mathrm{m}$. D shows higher magnification of the black boxed area in C. E shows higher magnification of the white boxed area in $\mathbf{D}$ ( $n=4 /$ group). (F) Mean abscess area $\left(\mathrm{cm}^{2}\right) \pm$ SEM and (C) mean bacterial band width $(\mathrm{mm}) \pm$ SEM from histologic sections $\left(n=4 /\right.$ group). (H) Draining LN cells harvested from d28 IL-1 $\beta^{-1-}$ mice and transferred i.v. 1 day prior to $1^{\circ} \mathrm{S}$. aureus inoculation of naive IL-1 $1 \beta^{-1-}$ mice and (I) mean total lesion size $\left(\mathrm{cm}^{2}\right) \pm \mathrm{SEM}$ and mean total flux (photon/s) \pm SEM ( $n=5$ /group). (J) Time line of anti-CD4 treatment and (K) mean total lesion size $\left(\mathrm{cm}^{2}\right) \pm \mathrm{SEM}$ and mean total flux (photon/s) \pm SEM $\left(n=5 /\right.$ group). ${ }^{\dagger} P<0.01$, compared with control $1^{\circ}$ or $2^{\circ}$ mice ( $\mathbf{B}$ and $\mathbf{I}$ ) as measured by 2 -way ANOVA. Results in $\mathbf{B}, \mathbf{I}$, and $\mathbf{K}$ are a compilation of 2 independent experiments.

fer or transfer of only $\gamma \delta \mathrm{T}$ cells (50,000 cells), only $\mathrm{CD} 4^{+} \mathrm{T}$ cells (5 million cells), or both $\gamma \delta$ and $\mathrm{CD} 4^{+} \mathrm{T}$ cells combined (Figure 5, C and D). Transfer of only $\gamma \delta \mathrm{T}$ cells had the same protective effect as shown in Figure 5B. However, transfer of only $\mathrm{CD} 4^{+} \mathrm{T}$ cells or $\gamma \delta$ and $\mathrm{CD} 4^{+} \mathrm{T}$ cells combined resulted in lesion sizes and in vivo bioluminescent signals that did not significantly differ from those of naive $\mathrm{IL}-1 \beta^{-/-}$mice, indicating that $\mathrm{CD} 4^{+} \mathrm{T}$ cells did not have a protective effect either alone or when combined with $\gamma \delta \mathrm{T}$ cells.
Mechanisms that induce protective $\gamma \delta T$ cells. Since protective $\gamma \delta$ $\mathrm{T}$ cells developed in the absence of IL-1 $\beta$ activity, we hypothesized that an alternative MyD88 signal induced their generation and/or expansion. We first evaluated IL-1 $\alpha$ because, like IL-1 $\beta$, it signals via IL-1R1/MyD88. To inhibit both IL-1 $\alpha$ and IL-1 $\beta$ activity, IL-1 $\beta^{-/-}$ mice were treated with an anti-IL-1R1 blocking antibody throughout the 42-day experiment (Figure 6, A and B). This treatment did not alter the $1^{\circ}$ infection outcome nor did it diminish the protection 
A
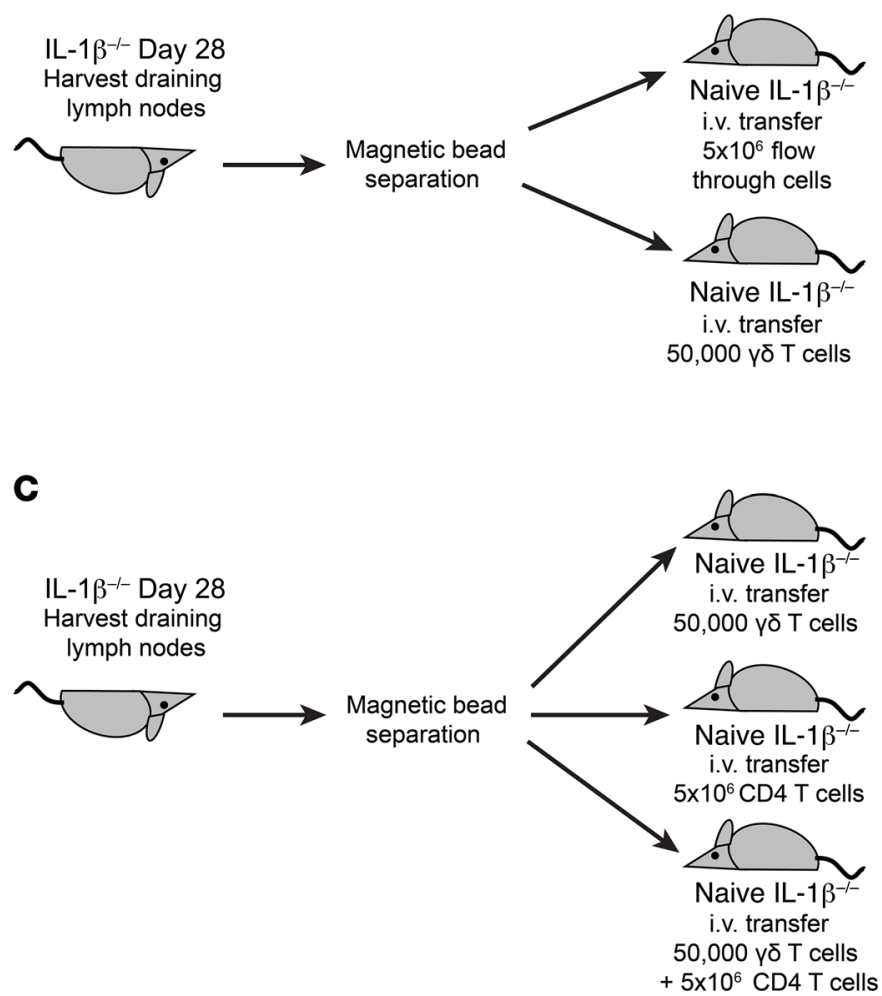

B
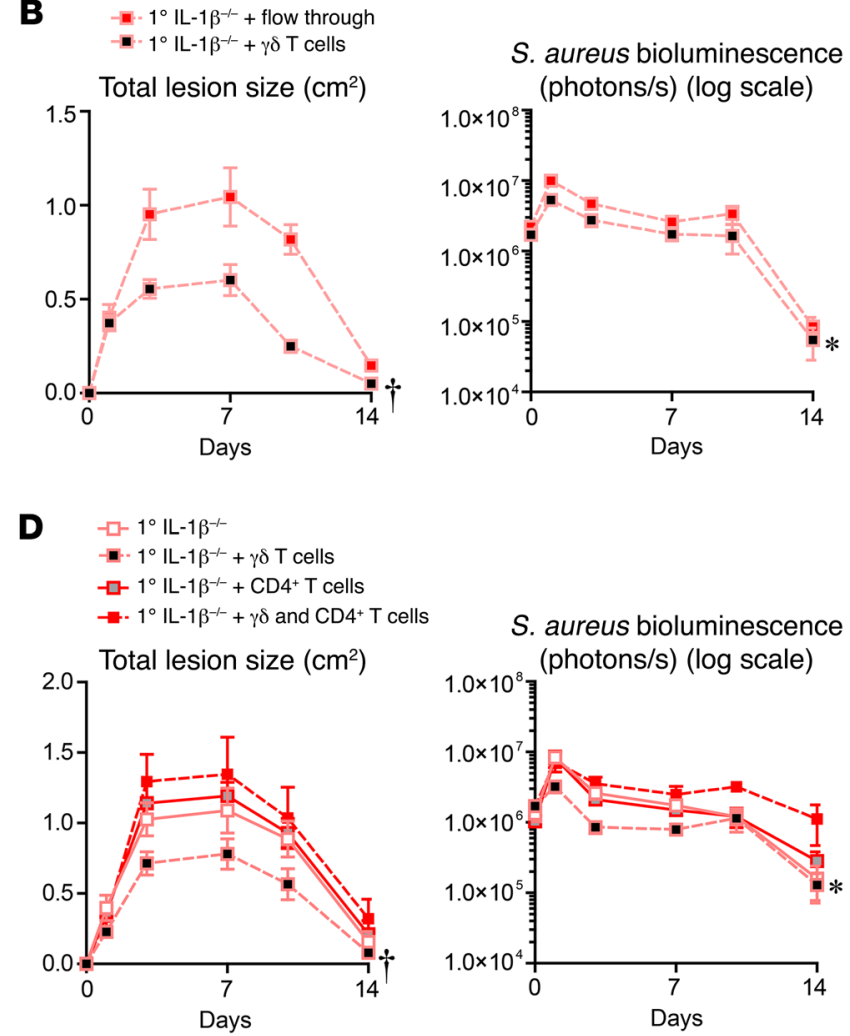

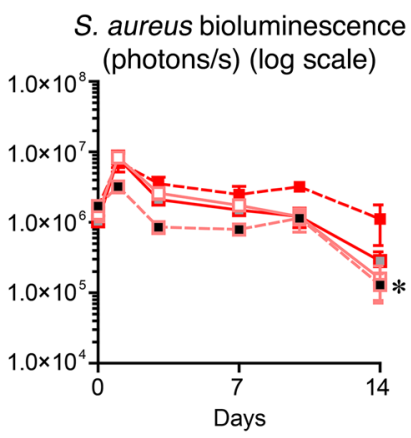

Figure 5. $\gamma \delta$ T cells from draining LNs confer protection. (A) Draining LNs were harvested from $\mathrm{d} 28 \mathrm{IL}-1 \beta^{-1-}$ mice, and $\gamma \delta \mathrm{T}$ cells or other CD $3^{+} \mathrm{T}$ cells were transferred i.v. 1 day prior to S. aureus inoculation of naive IL-1 $\beta^{-/-}$mice. (B) Total lesion size $\left(\mathrm{cm}^{2}\right) \pm \mathrm{SEM}$ and mean total flux (photon/s) \pm SEM $(n=10 /$ group). (C) Draining LNs were harvested from d28 IL-1 $\beta^{-1-}$ mice and $\gamma \delta$ T cells, CD4+ $T$ cells, or $\gamma \delta$ T cells and CD4 ${ }^{+}$T cells combined were transferred i.v. 1 day prior to S. aureus inoculation of naive IL-1 $1 \beta^{-/-}$mice. (D) Total lesion size $\left(\mathrm{cm}^{2}\right) \pm \mathrm{SEM}$ and mean total flux (photon/s) \pm SEM $\left(n=5 /\right.$ group). ${ }^{*} P<0.05 ;{ }^{\dagger} P<$ 0.01 , between the 2 groups (B) or compared with IL-1 $\beta^{-1-}$ mice without cell transfer $\left(1^{\circ} \mathrm{IL}-1 \beta^{-1-}\right)$ (D) as measured by 2 -way ANOVA. Results in $\mathbf{B}$ are a compilation of 2 independent experiments, and results in $\mathbf{D}$ are representative of 2 independent experiments.

observed in $2^{\circ} \mathrm{IL}-1 \beta^{-/-}$mice, indicating that IL-1 $\alpha$ was not involved in the protection. Next, a role for TLR2, which recognizes S. aureus lipopeptides, lipoteichoic acid (LTA), and peptidoglycan (PGN) (6), was evaluated by treating TLR2 $\%$ mice with an anti-IL-1R1 blocking antibody (Figure 6, C and D). Under these conditions, both TLR2 and IL-1R1 activity were blocked and this resulted in loss of protection during the $2^{\circ}$ infection, indicating that TLR2 compensated for the lack of IL-1 $1 \beta$ to promote the protective response. Consistent for a role of TLR2 on $\gamma \delta \mathrm{T}$ cells, an appreciable percentage of $\gamma \delta \mathrm{T}$ cells in LNs of naive and $\mathrm{d} 28 \mathrm{IL}-1 \beta^{-/}$mice expressed TLR2, especially compared with the almost complete absence of TLR2 expression on $\mathrm{CD}_{4}^{+} \mathrm{T}$ cells (Figure 6, $\mathrm{E}$ and F). Furthermore, to evaluate for intrinsic TLR2/MyD88 signaling in T cells, $1^{\circ}$ and $2^{\circ} \mathrm{S}$. aureus skin infections were induced in Lck-cre $\times$ MyD8 $88^{\mathrm{t} / \mathrm{Il}}$ mice, which have MyD88 specifically deleted in all T cell subsets, including $\gamma \delta \mathrm{T}$ cells (Figure 6, G and H). Lck-cre $\times$ MyD8 $88^{\mathrm{A} / \mathrm{ll}}$ mice had a marked host defense impairment during the $1^{\circ}$ infection and completely failed to develop any protective response during a $2^{\circ} \mathrm{S}$. aureus skin infection, suggesting that $\mathrm{T}$ cell-intrinsic MyD88 signaling was required for mediating the protective response. Thus, TLR2 provided an alternative MyD88 signal in T cells that contributed to the protection observed in $2^{\circ} \mathrm{IL}-1 \beta^{-/}$mice.

TNF and IFN- $\gamma$, but not IL-17 or IL-22, mediate protection. To identify the effector cytokines produced by the protective $\gamma \delta \mathrm{T}$ cells, total LN cells from naive and $\mathrm{d} 28 \mathrm{WT}$ and $\mathrm{IL}-1 \beta^{-/-}$mice were stimulated ex vivo with PMA/ionomycin and intracellular FACS was performed. IL-17A and IL-22 were first evaluated because they have been reported to be produced by trafficking $\gamma \delta \mathrm{T}$ cells (primarily in an IL-1 $\beta$ - and IL-23-dependent manner) during S. aureus skin infections (16), skin inflammation $(24,29-31)$, or after repeated intraperitoneal exposure to $S$. aureus (32). LN cells from $\mathrm{d} 28 \mathrm{IL}-1 \beta^{-/}$mice had either unchanged or decreased percentages of $\mathrm{IL}^{-17 \mathrm{~A}^{+}}$and $\mathrm{IL}-22^{+} \gamma \delta \mathrm{T}$ cells compared with naive $\mathrm{IL}-1 \beta^{--}$mice (Figure 7, A and B). Certain circulating $\gamma \delta \mathrm{T}$ cell subsets can produce TNF or IFN- $\gamma$ (33-35); however, it is unknown whether TNF- and/or IFN- $\gamma$-producing $\gamma \delta$ T cells developed after exposure to $S$. aureus and contributed to the protection observed. LN cells from d $28 \mathrm{IL}-1 \beta^{-/-}$mice had significantly increased percentages of $\mathrm{TNF}^{+}$and $\mathrm{TNF}^{+} \mathrm{IFN}-\gamma^{+} \gamma \delta \mathrm{T}$ cells compared with naive $\mathrm{IL}-1 \beta^{--}$mice (Figure 7, A and B). In contrast, LN cells from d 28 WT mice had an increased percentage of IL-17A $\mathrm{A}^{+} \delta$ T cells and had either unchanged or decreased percentages of IL-22+, $\mathrm{TNF}^{+}$, and $\mathrm{TNF}^{+} \mathrm{IFN}-\gamma^{+} \gamma \delta \mathrm{T}$ cells compared with naive WT mice.

To evaluate whether these responses were relevant in vivo, these cytokine protein levels were measured in the S. aureus-infected skin of $\mathrm{IL}^{-1} \beta^{-/-}$and WT mice (Figure $7 \mathrm{C}$ ). In $2^{\circ} \mathrm{IL}-1 \beta^{-/}$mice, TNF and IFN- $\gamma$ levels increased 5- and 2-fold, respectively, whereas IL-17A and IL-22 levels were not significantly different than in $1^{\circ} \mathrm{IL}-1 \beta^{-/-}$ 
A

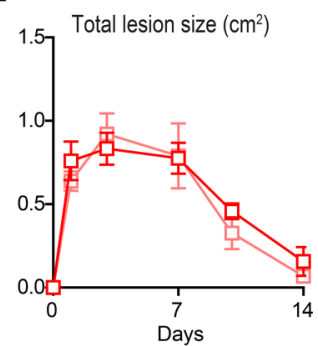

C

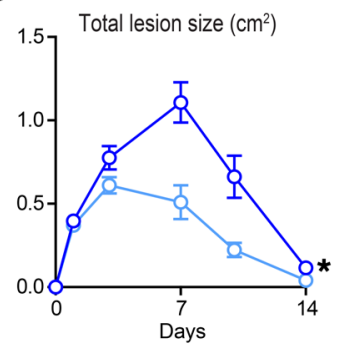

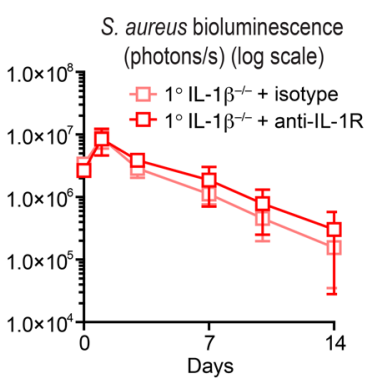

S. aureus bioluminescence

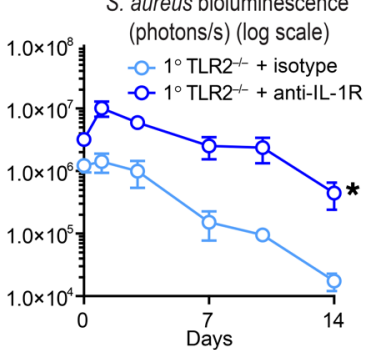

E

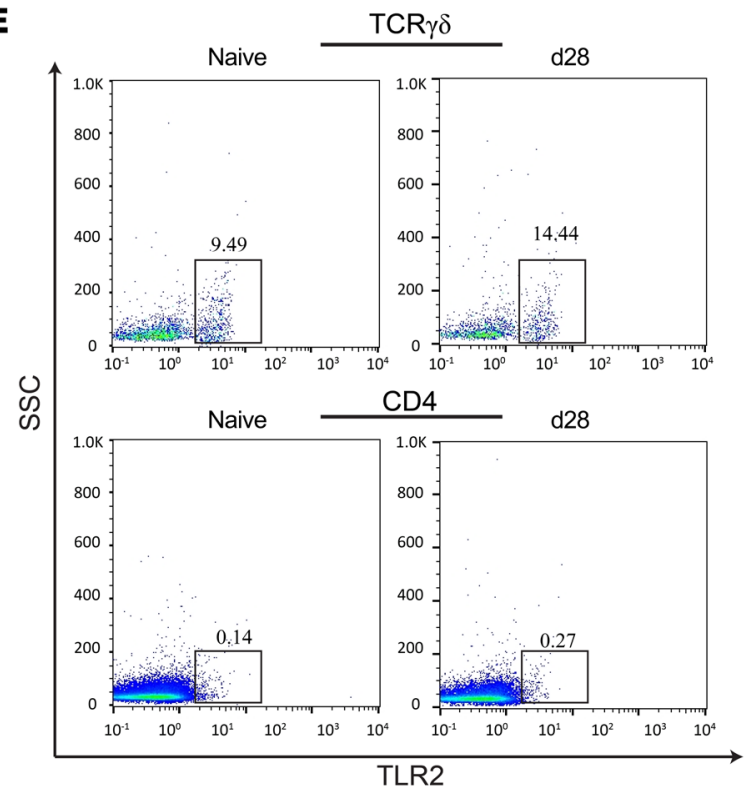

Figure 6. $\gamma \delta$ T cells are induced by T cell-intrinsic TLR2/MyD88 signaling. $\mathrm{IL}^{-1} \beta^{-1-}$ mice (A and $\mathbf{B}$ ) or TLR2 ${ }^{-1-}$ mice (C and $\mathbf{D}$ ) were treated with an $\alpha-\mathrm{IL}-1 \mathrm{R}$ antibody or isotype control every other day beginning at $\mathrm{d}-1$ and continuing throughout the $1^{\circ}$ and $2^{\circ}$ infection with total lesion size $\left(\mathrm{cm}^{2}\right) \pm$ SEM and mean total flux (photon/s) \pm SEM ( $n=5 /$ group) determined. (E and F) Representative flow plots $(\mathbf{E})$ and mean percentage \pm SEM (F) of TLR2-expressing $\gamma \delta$ and $\mathrm{CD} 4^{+}$T cells in inguinal LNs of naive and $\mathrm{d} 28 \mathrm{IL}-1 \beta^{-/-}$mice $(n=5 /$ group). ( $(\mathbf{G}$ and $\mathbf{H})$ Lck-MyD8 $8^{-1-}$ or WT mice $(n=5)$ during $1^{\circ}$ and $2^{\circ}$ infection with mean total lesion size $\left(\mathrm{cm}^{2}\right) \pm S E M$ and mean total flux (photon $\left./ \mathrm{s}\right) \pm$ SEM ( $n=5$ /group) determined. ${ }^{*} P<0.05 ;{ }^{\dagger} P<0.01$, compared with control $1^{\circ}$ or $2^{\circ}$ mice as measured by 2 -way ANOVA. Results $(\mathbf{A}-\mathbf{H})$ are representative of 2 independent experiments.

mice. In contrast, IL-17A, IL-22, TNF, and IFN- $\gamma$ levels were not significantly different between $1^{\circ}$ and $2^{\circ} \mathrm{WT}$ mice. Finally, treatment of $2^{\circ} \mathrm{IL}^{-1} \beta^{-/}$mice with a combination of anti-TNF and anti-IFN- $\gamma$ neutralizing antibodies resulted in loss of protection (Figure 7D), indicating that TNF and/or IFN- $\gamma$ were crucial for mediating protection.
B

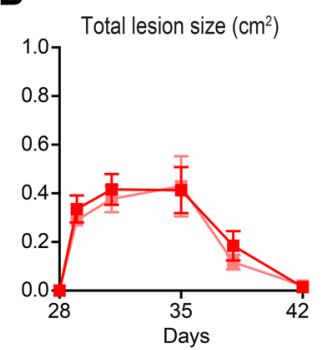

D
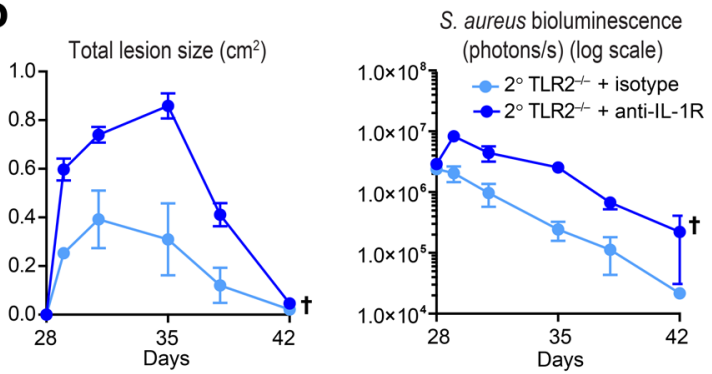

$\mathbf{F}$
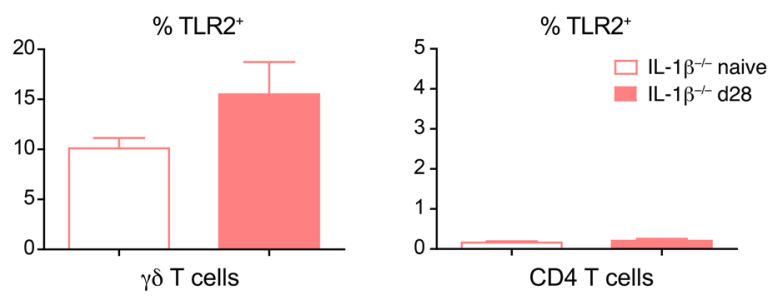

G
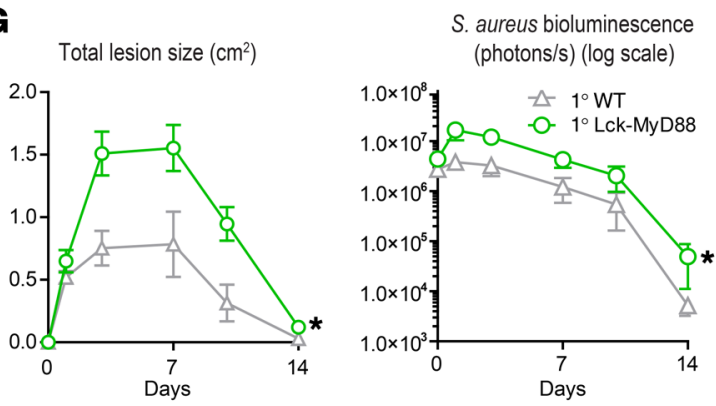

H
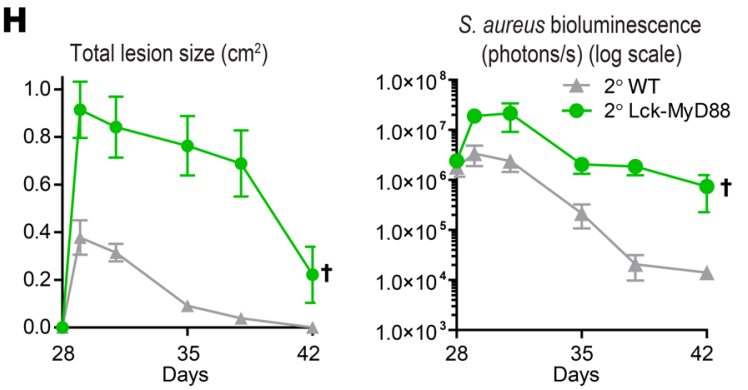

$\gamma \delta$ T cells clonally expand in LNs following S. aureus skin infection. TCR complementarity-determining region 3-encoding (CDR3-encoding) sequences were mined from RNA-sequencing (RNA-seq) data sets of naive and $\mathrm{d} 28 \mathrm{WT}$ and $\mathrm{IL}-1 \beta^{-/-}$mice for T cell repertoire analysis (Figure 8, A and B). The LNs of naive WT and IL-1 $1 \beta^{-/-}$mice 
A
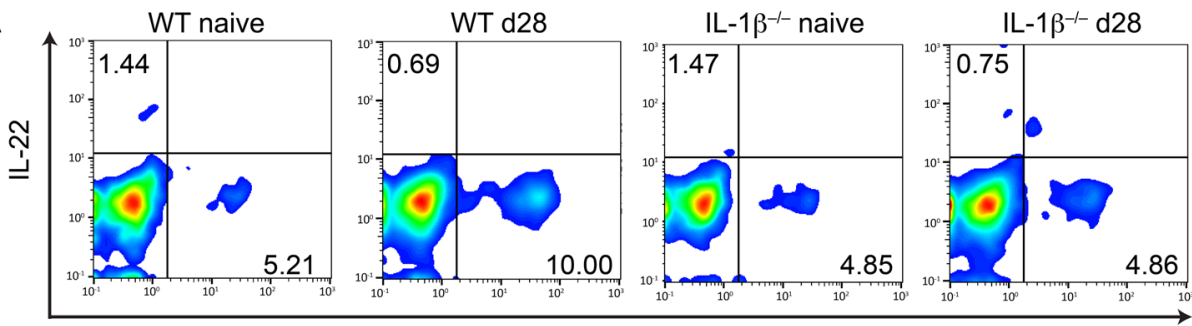

IL-17A
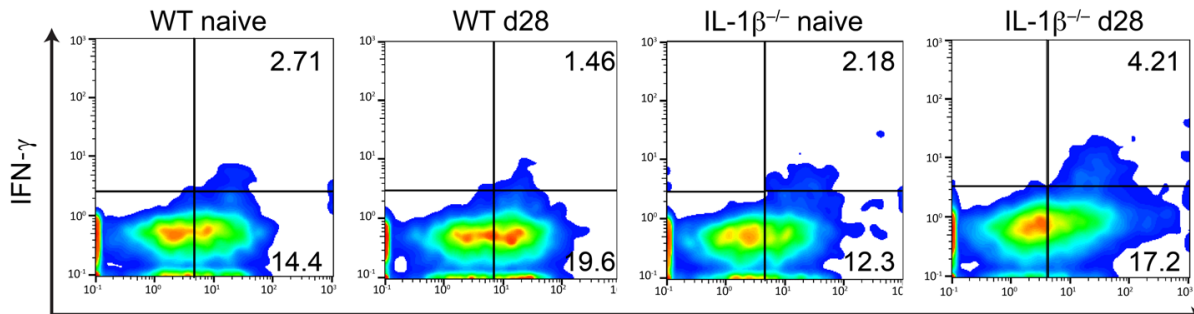

TNF

B
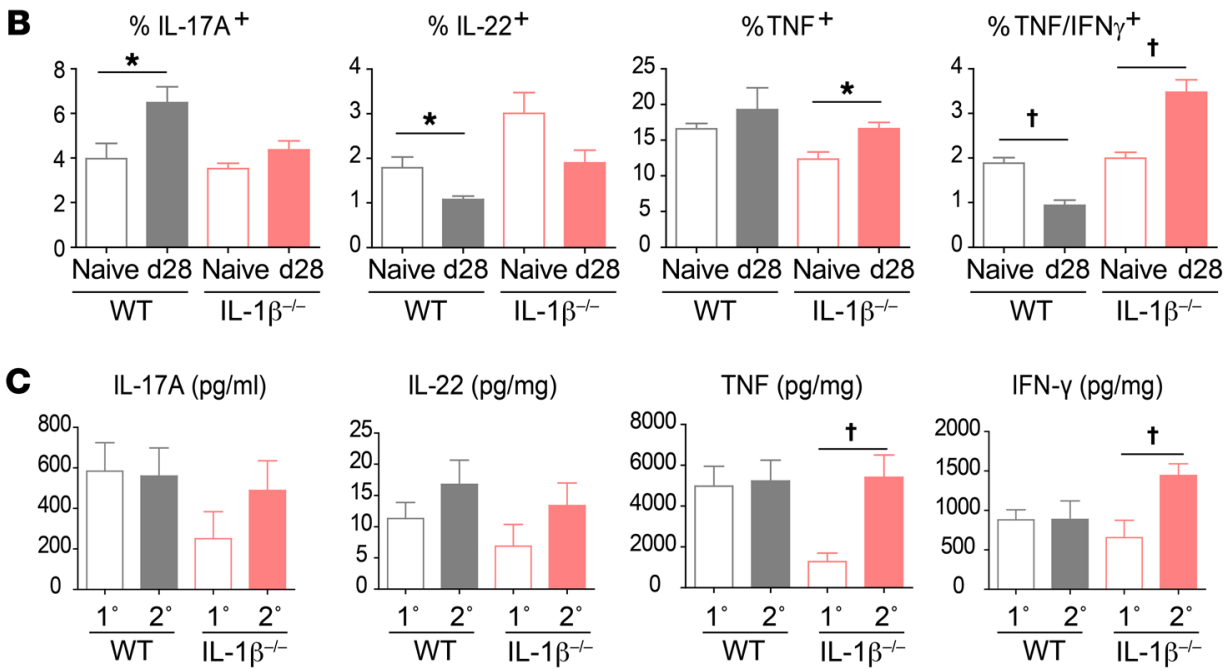

D

Total lesion size $\left(\mathrm{cm}^{2}\right)$
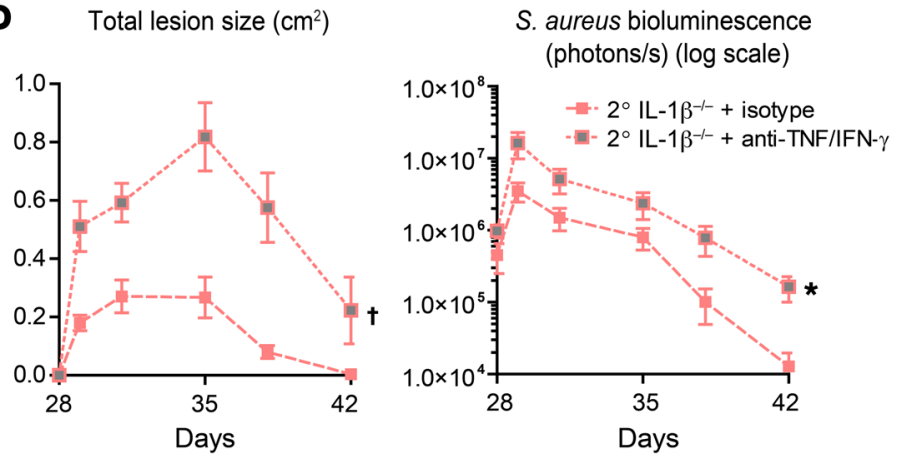

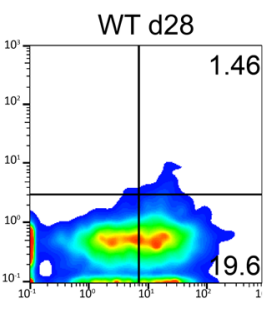

Figure 7. $\gamma \delta$ T cells produced TNF and IFN- $\gamma$ to mediate protection. (A and $\mathbf{B}$ ) Representative flow plots $(\mathbf{A})$ and mean percentage \pm SEM (B) are shown for IL-17A-, IL-22-, TNF-, and IFN- $\gamma$-producing $\gamma \delta \mathrm{T}$ cells in inguinal $\mathrm{LNs}$ of naive and $\mathrm{d} 28$ WT and IL-1 $\beta^{-/-}$mice ( $n=5$ /group). (C) Protein levels of IL17A, IL-22, TNF, and IFN- $\gamma$ in skin homogenates at d1 after S. aureus inoculation ( $n=5 /$ group). (D) Mean total lesion size $\left(\mathrm{cm}^{2}\right) \pm$ SEM and mean total flux (photon/s) \pm SEM of IL-1 $\beta^{-/-}$mice \pm anti-TNF/IFN- $\gamma$ treatment ( $n=5$ /group). ${ }^{*} P<0.05 ;{ }^{\dagger} P<0.01$, as calculated by 2-tailed Student's $t$ test (B and C) or 2-way ANOVA (D). Results are representative of 2 independent experiments.

"top" (dominant) CDR3-encoding reads for TCR $\gamma$ (TRG) (CACWDSSGFHKVF) and TRD (CGSDIGGSSWDTRQMFF), which represented approximately $20 \%$ of the total TRG and TRD CDR3-encoding sequences in the LNs following $S$. aureus skin infection (Figure 8B). The frequency of the TRG CACWDSSGFHKVF CDR3 aa sequence was increased in skin-draining LNs of 5 of $5 \mathrm{~d} 28$ WT mice and 6 of $7 \mathrm{~d} 28 \mathrm{IL}-1 \beta^{-/-}$mice (Figure $8 \mathrm{~B}$ ) and was encoded by different TRG gene rearrangements, indicating that the expansion arose from multiple $\gamma \delta$ T cells rather than a single clone. For example, while there were "canonical" TRG CACWDSSGFHKVF-encoding TCR gene rearrangements lacking $\mathrm{N}$ additions, this CDR3 aa sequence was also encoded for by gene rearrangements containing $\mathrm{N}$ additions (Table 1). Furthermore, this CDR3 aa sequence was encoded by 2 different $3^{\prime} \mathrm{V}$ regions, TRGV5 and TRGV6 (Table 2), again indicating clonotypic $\mathrm{T}$ cell expansion. Curiously, a single $\mathrm{d} 28 \mathrm{IL}-1 \beta^{-/-}$mouse did not expand the TRGV5/6-encoded CACWDSSGFHKVF sequence in response to $S$. aureus, but instead

had diverse $\alpha \beta$ and $\gamma \delta$ T cell repertoires. In LNs of uninfected mice, there were "public" (present in multiple mice) CDR3 aa sequences encoded by TRA (CVVGDRGSALGRLHF) and TRB (CASSLGGNYAEQFF) at low frequencies ( $0.5 \%$ and $\sim 0.1 \%$, respectively), but these did not expand following $S$. aureus skin infection. In LNs of $\mathrm{d} 28 \mathrm{WT}$ and $\mathrm{IL}-1 \beta^{-/-}$mice, TRA and TRB repertoire analysis revealed no significant public $S$. aureus-induced expansions (Figure $8 \mathrm{~A})$. In contrast, LNs of $\mathrm{d} 28 \mathrm{WT}$ and $\mathrm{IL}-1 \beta^{-/-}$mice exhibited strong $\gamma \delta \mathrm{T}$ cell expansions, as evidenced by the emergence of utilized TRGV1 and TRGV3 gene segments to generate similar CDR3 aa sequences (i.e., CAVWTYSSGFHKVF and CAVWLYSSGFHKVF). The top TRD4 (CGSDIGGSSWDTRQMFF) CDR3 aa sequence also exhibited clonotypic expansion, as it was encoded by gene rearrangements with and without $\mathrm{N}$ additions in all $\mathrm{d} 28$ WT and IL-1 $\beta^{-/-}$mice (Tables 3 and 4 ).

To verify these results, we mined the RNA-seq data set of Brady et al., which evaluated $S$. aureus-infected ear skin of WT mice on $\mathrm{d} 0, \mathrm{~d} 1, \mathrm{~d} 4$, and $\mathrm{d} 7 \mathrm{(36)}$. This revealed the same clono- 
A

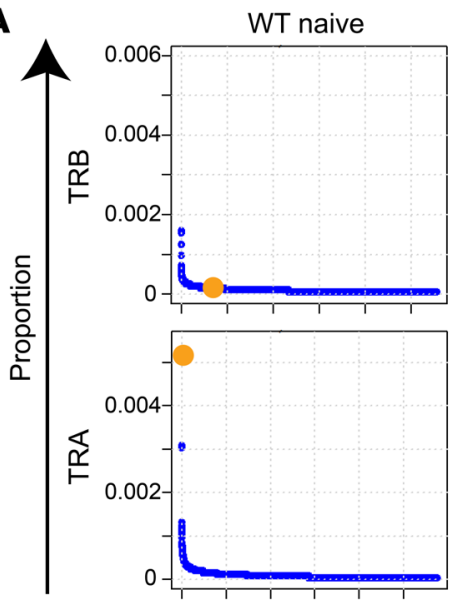

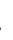

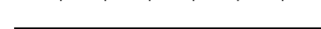

\section{B}

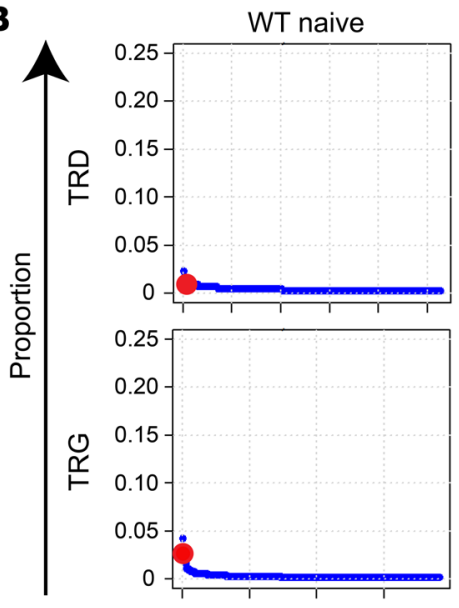

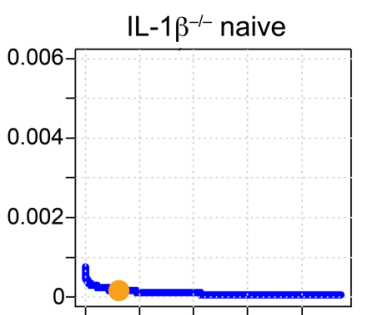

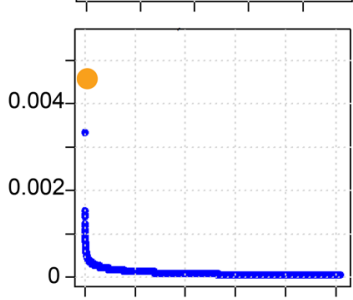

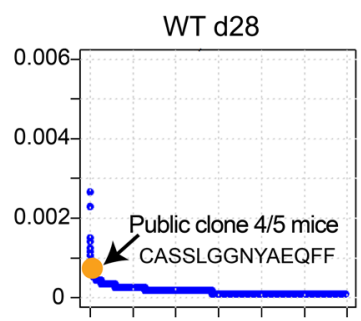
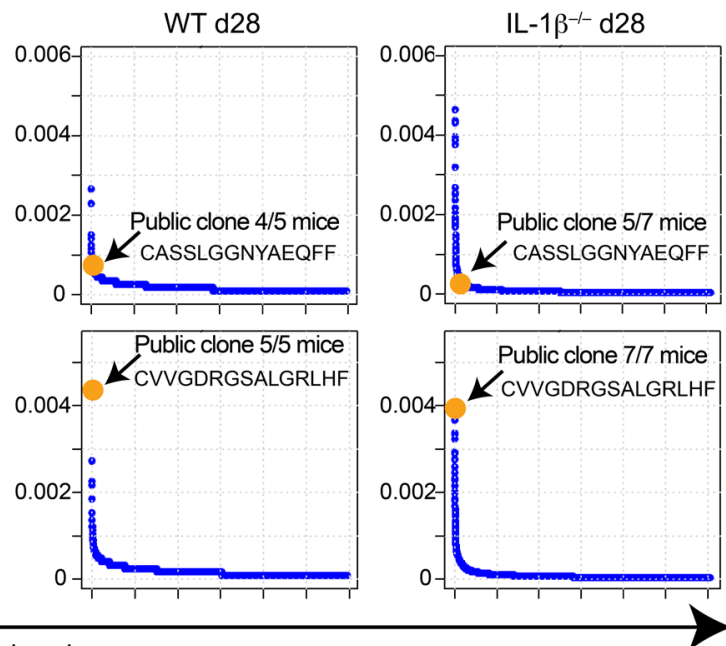

Rank order
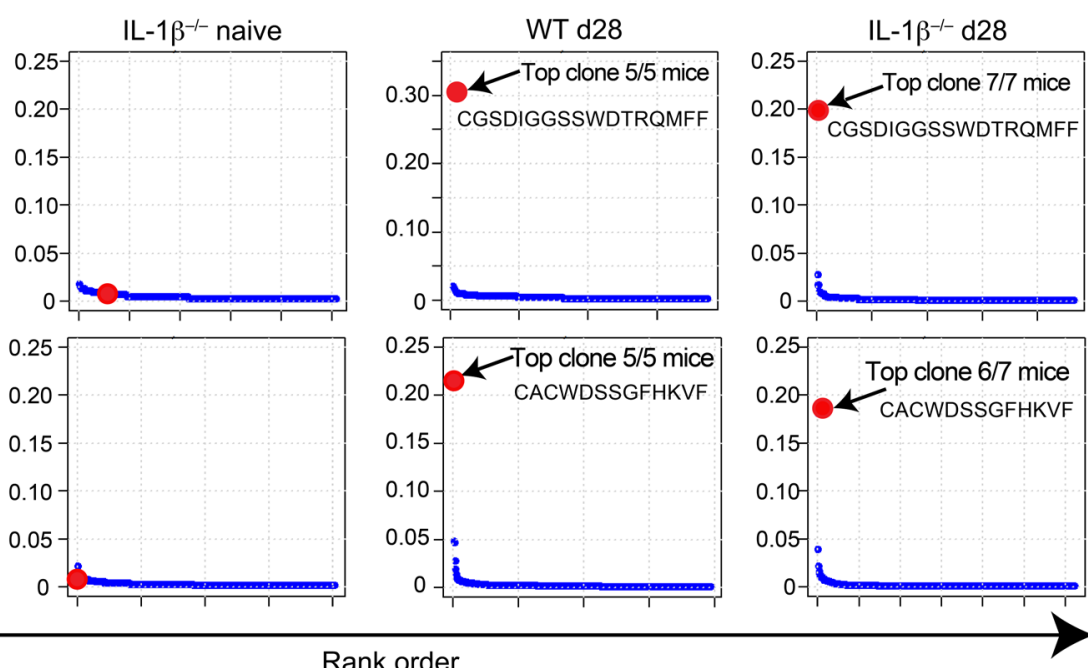

Rank order

Figure 8. Clonotypic T cell expansion in response to S. aureus. CDR3 sequences were mined from RNA-seq data set of LNs and skin samples of naive WT and IL-1 $\beta^{-1-}$ mice ( $n=5$ /group) and d28 LNs (WT mice, $n=5$; IL-1 $1 \beta^{-1-}$ mice, $n=7$ ). (A and B) Pooled results from all LN samples presented as the CDR3 aa sequence rank ( $x$ axis) versus proportion of the total CDR3 aa reads occupied by that particular CDR aa sequence ( $y$ axis). Blue dots indicate each of the different CDR3 aa reads; orange dots indicate public (found in most samples) TRA- and TRB-encoded CDR3 aa sequences; red dots indicate top (dominantly expanded) TRG- and TRD-encoded CDR3 aa sequences in d28 LNs of WT and IL-1 $1 \beta^{-1 /}$ mice.

typic TRG5/6-encoded CACWDSSGFHKVF sequence (Table 1), demonstrating that the clones detected in our experiments were also found in naive and $S$. aureus-infected WT skin in a separate mouse colony. We also performed CDR3-dedicated $\mathrm{T}$ cell repertoire analysis of skin samples obtained from WT and IL-1 $\beta^{-/}$naive mice and $\mathrm{d} 31 \mathrm{IL}-1 \beta^{-/-}$mice $\left(3\right.$ days after the $2^{\circ} \mathrm{S}$. aureus inoculation). In all cases, the TRGV5/6-encoded CACWDSSGFHKVF sequence and the TRDV4-encoded CGSDIGGSSWDTRQMFF sequence were detected (Tables 1 and 3), indicating that the same clonotypic $\gamma \delta \mathrm{T}$ cells were present in the skin both at baseline and during the $2^{\circ}$ infection in WT and IL-1 $1 \beta^{-/-}$mice. Importantly, the TRGV5/V6-encoded CACWDSSGFHKVF and TRDV4-encoded CGSDIGGSSWDTRQMFF clonotypes were detected as unexpanded members of the skin-draining LNs of naive WT and $\mathrm{IL}-1 \beta^{-/-}$mice (Figure 8B), indicating that these skin-resident $\gamma \delta \mathrm{T}$ cell clones were also low-frequency members of the peripheral $\mathrm{T}$ cell repertoire prior to infection.
The Spearman's rank-order correlation coefficient was used to determine correlations between reads mapping to the TRGV5/ V6-encoded CACWDSSGFHKVF sequence or the TRDV4-encoded CGSDIGGSSWDTRQMFF sequence and reads mapping to the $\mathrm{T}$ cell-associated transcription factors TBX21, RORC, GATA3, and FOXP3 (Table 5). The only significant positive correlations were between the 2CDR3-encoding transcripts and TBX21, which encodes for the IFN- $\gamma$-inducing transcription factor T-bet, consistent with the increased percentage of IFN- $\gamma^{+} \gamma \delta$ T cells in LNs of d $28 \mathrm{IL}-1 \beta^{-/-}$mice (Figure 6, A and B). There were also significant negative correlations between the TRV5/TRV6 CDR3 transcripts and GATA3 $(P<0.05)$, which encodes for a Th2 cytokine-inducing transcription factor.

Finally, TRGV4-encoded CDR3 sequences detected in the skin were compared with those detected in the LNs before and after the S. aureus skin infection. These cells were singled out for additional analysis because prior reports found that resident and recruited dermal $\gamma \delta \mathrm{T}$ cells in response to inflammation or infection com- 
Table 1. TRG nt sequence alignments

\begin{tabular}{|c|c|c|c|c|c|c|c|c|c|}
\hline No. & Gene & V & J & CDR3 nt & CDR3 aa & WT LN & IL-1 $\beta^{-/-}$LN & WT skin ${ }^{A}$ & IL-1 $\boldsymbol{\beta}^{-/-}$skin \\
\hline 1 & TRG & V5 & J1 & $\begin{array}{l}\text { TGTGCCTGCTGGGATAGCTCA } \\
\text { GGTTTTCACAAGGTATTT }\end{array}$ & $\begin{array}{l}\text { CACWDS } \\
\text { SGFHKVF }\end{array}$ & + & + & + & + \\
\hline 2 & $T R G$ & V6 & 11 & $\begin{array}{l}\text { TGTGCATGCTGGGATAGCTCA } \\
\text { GGTTTTCACAAGGTATTT }\end{array}$ & $\begin{array}{l}\text { CACWDS } \\
\text { SGFHKVF }\end{array}$ & + & + & + & + \\
\hline 3 & TRG & V6 & 11 & $\begin{array}{l}\text { TGTGCATGCTGGGATAGCTCT } \\
\text { GGTTTTCACAAGGTATTT }\end{array}$ & $\begin{array}{l}\text { CACWDS } \\
\text { SGFHKVF }\end{array}$ & - & + & - & - \\
\hline
\end{tabular}

${ }^{A}$ Brady et al. (36). TRGV5 and TRGV6 nt sequences and gene-sequence alignments of the different clonotypes from the top TRG-encoded CDR3 aa sequence in Figure $8 \mathrm{~B}$ and ref. 36. Bold indicates nt differences.

prised IL-17-producing $\mathrm{V} \gamma 4^{+} \gamma \delta$ T cells (24, 29-31). Although the TRGV4 population was diverse, there were several public clones, the most common of which was a TRGV4/TRGJ1 clone whose CDR3 aa sequence was CSYGYSSGFHKVF. This clone was detected in $100 \%$ of the LN samples and $50 \%$ of the skin samples from naive IL-1 $\beta^{-/-}$and WT mice. However, it was not expanded in the $\mathrm{d} 28 \mathrm{IL}-1 \beta^{-/-}$mice following $S$. aureus skin infection.

Humans with IRAK4 deficiency have a similar population of circulating $\gamma \delta T$ cells. To ascertain whether similar TNF/IFN- $\gamma$ circulating $\gamma \delta$ T cells exist in humans, peripheral blood was evaluated from healthy individuals and individuals with primary immunodeficiency disorders with an increased susceptibility to $S$. aureus skin infections and other pyogenic infections, including IRAK4 deficiency with impaired neutrophil migration due to defective IL-1R/TLR signaling (including a lack of IL-1 $1 \beta$ activity, as in IL-1 $1 \beta^{-/-}$mice) $(7,8)$ and chronic granulomatous disease (CGD) with defective neutrophil killing due to loss-of-function mutations in NADPH oxidase (37). Healthy and IRAK4-deficient individuals had $1 \%-5 \% \gamma \delta \mathrm{T}$ cells, whereas individuals with CGD had only approximately $1 \% \gamma \delta \mathrm{T}$ cells of the total $\mathrm{CD}^{+} \mathrm{T}$ cell population (Figure 9, A and B). Healthy individuals had virtually equivalent percentages $(\sim 45 \%)$ of $\mathrm{V} \delta 1^{+}$and $\mathrm{V} \delta 2^{+} \gamma \delta \mathrm{T}$ cells (Figure $9, \mathrm{C}$ and $\mathrm{D}$ ), which are the major $\gamma \delta \mathrm{T}$ cell populations in human blood (33-35). $\gamma \delta \mathrm{T}$ cells were mostly V $\delta 2^{+}(>80 \%)$ in IRAK4 deficiency, and in contrast, the few $\gamma \delta \mathrm{T}$ cells in CGD were mostly

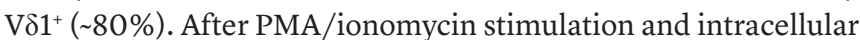
FACS analysis, the percentages of TNF- and/or IFN- $\gamma$-producing cells were evenly distributed (20\%-35\%) among V $\delta 2^{+}$and $\mathrm{V} \delta 1^{+}$ cells in healthy individuals. In contrast, almost all of TNF- and/ or IFN- $\gamma$-producing cells (88\%-96\%) were V $\delta 2+$ cells in IRAK4 individuals and a broad range of TNF- and/or IFN- $\gamma$-producing cells (38\%-92\%) were V $81+$ cells in CGD individuals (Figure 9, E-H). The cellular phenotype of blood drawn from the IRAK4 patient at the end of and several years after her recurrent infections was very stable. Interestingly, the percentage of $\gamma \delta \mathrm{T}$ cells that produced IL-17A among all human experimental groups was less than $0.68 \%$, which was 50 - to 100 -fold lower than the percentage of TNF and/or IFN- $\gamma$-producing $\gamma \delta$ T cells (Figure 9, I and $\mathrm{J}$ ), indicating that IL-17A is not a major cytokine produced by circulating $\gamma \delta$ T cells in humans.

\section{Discussion}

The immune mechanisms that mediate long-lasting protection to $S$. aureus skin infections have remained elusive, especially since recurrences are common despite the generation of high titers of specific antibodies and memory $\alpha \beta$ T cells $(3,4)$. In the present study, we utilized $S$. aureus-susceptible IL-1 $1 \beta^{-/}$mice with impaired neutrophil recruitment and IL-17 responses to elucidate host defense mechanisms that provide durable protection against an $S$. aureus skin reinfection. We report that, following an initial S. aureus skin infection, clonotypic TNF/IFN- $\gamma$-producing $\gamma \delta \mathrm{T}$ cells expanded in skin-draining LNs and protected against a subsequent $S$. aureus skin challenge, which likely complements the previously characterized antibody and IL-17 responses in immunity to $S$. aureus skin infections (15-18). This $\gamma \delta \mathrm{T}$ cell protective response was long lived, as it was still present at 20 weeks, similar to $\alpha \beta \mathrm{T}$ cell memory responses in other models $(38,39)$. The protection was specific to $\gamma \delta \mathrm{T}$ cells, since transfer of $\gamma \delta \mathrm{T}$ cells, but not serum containing S. aureus-specific antibodies, $\mathrm{CD} 4^{+} \mathrm{T}$ cells, or primed neutrophils from previously infected IL-1 $1 \beta^{-/}$mice, rescued the immune impairment of naive IL-1 $1 \beta^{-/-}$mice.

In mice, $\gamma \delta \mathrm{T}$ cells have been increasingly recognized as contributing to both innate and adaptive immune responses (33-35). During development, murine $\gamma \delta \mathrm{T}$ cells leave the thymus, possess invariant TCRs, and populate various epithelial sites in tissues and organs (33-35), such as the $\mathrm{V} \gamma 5^{+} \gamma \delta \mathrm{T}$ cells in mouse epidermis (40).

\section{Table 2. Analysis of TRG CDR3 V-J junction}

\begin{tabular}{|c|c|c|c|c|c|}
\hline No. & V name & $3^{\prime} \mathrm{V}$ region & $\mathbf{N}$ & $5^{\prime}$ J region & J name \\
\hline 1 & $\operatorname{TRGV5}{ }^{*} 01$ & TGTGCCTGCTGGGAT. & & .. AGCTCAGGTTTTCACAAGGTATTT & $\operatorname{TRC} / 1 * 01$ \\
\hline 2 & $\operatorname{TRGVG}^{*} 01$ & TGTGCATGCTGGGATA & & ...GCTCAGGTTTTCACAAGGTATTT & $\operatorname{TRC} J 11^{*} 01$ \\
\hline 3 & TRGV6*01 & TGTGCATGCTGGGATA & GСTCт & ........GGTTTTCACAAGGTATTT & $\operatorname{TRCJ} 1 * 01$ \\
\hline
\end{tabular}

TRGV5 and TRGV6 nt sequences of the 3' $\mathrm{V}$ region and 5' J region from the top TRG-encoded CDR3 aa sequence in Figure 8B. Germline residues not depicted are shown as periods (each individual period indicates a single unincorporated germline nucleotide). Bold indicates nt differences. 
Table 3. TRD nt sequence alignments

\begin{tabular}{|c|c|c|c|c|c|c|c|c|c|}
\hline No. & Gene & V & J & CDR3 nt & CDR3 aa & WT LN & IL-1 $1 \beta^{-/-}$LN & WT skin ${ }^{A}$ & IL-1/ $\boldsymbol{\beta}^{-/-}$skin \\
\hline 1 & $T R D$ & V4 & 12 & $\begin{array}{l}\text { TGTGGGTCAGATATC } \\
\text { GGAGGGAGCTCCTG } \\
\text { GGACACCCGACAGA } \\
\text { TGTTTTTT }\end{array}$ & $\begin{array}{l}\text { CGSDIGGSS } \\
\text { WDTRQMFF }\end{array}$ & + & + & + & + \\
\hline 2 & $T R D$ & V4 & 12 & $\begin{array}{l}\text { TGTGGCTCAGATATC } \\
\text { GGAGGGAGCTCCTG } \\
\text { GGACACCCGACAGA } \\
\text { TGTTTTTT }\end{array}$ & $\begin{array}{l}\text { CGSDIGGSS } \\
\text { WDTRQMFF }\end{array}$ & - & - & + & - \\
\hline
\end{tabular}

${ }^{A}$ Brady et al. (36). TRD nt sequences and gene sequence alignments of the different clonotypes from the top TRD-encoded CDR3 aa sequence in Figure 8B and Brady et al. (36). Bold indicates nt differences.

In general, circulating murine $\gamma \delta \mathrm{T}$ cells produce IL-17 or IFN- $\gamma$, with IL-1 $\beta /$ IL-1R1 activation promoting IL-17 production $(16,29$, $32,41)$. Since data in humans indicate that protective immunity to recurrent $S$. aureus skin infections can develop in the absence of MyD88/IRAK4 signaling (including IL-1ß/IL-1R1/MyD88 signaling) (19) and Th17/IL-17 responses (20), we evaluated IL-1 $\beta$ deficient mice to uncover previously unknown components of the $S$. aureus-directed immune response.

We found an important role for TNF and IFN- $\gamma$ in protecting against a secondary $S$. aureus skin challenge, which was unexpected because TNF- $\alpha \mathrm{RI}^{-/-}$and IFN- $\gamma \mathrm{R}^{-/-}$mice were found to have no immune impairment against a $1^{\circ} S$. aureus skin infection $(14,16)$. However, a recent report found that deficiency in both IFN- $\gamma$ and IL-17 signaling, but not either alone, resulted in spontaneous and persistent mucocutaneous $S$. aureus infections in mice (42), suggesting that both IFN- $\gamma$ and IL-17 are required for durable protection against $S$. aureus skin infections. Furthermore, impaired Th1 responses (i.e., IFN- $\gamma^{+} \mathrm{CD} 4^{+} \mathrm{T}$ cells), but not IL-17/Th17 cell responses, were observed in the blood and $S$. aureus-infected skin of $\mathrm{HIV}^{+}$individuals (known to be highly susceptible to $S$. aureus skin infections), implicating IFN- $\gamma$ rather than IL-17 in mediating protective immunity to $S$. aureus skin infections in humans (26). These data in mice and humans support our finding that TNF and IFN- $\gamma$ responses are essential for long-lasting immunity against $S$. aureus skin infections.

In this study, TLR2 compensated for the lack of IL-1 $\beta$, since the protection observed in the $2^{\circ} \mathrm{IL}-1 \beta^{-/-}$mice was lost when both IL-1R1 and TLR2 were inhibited in vivo. In addition, TLR2 was expressed by $\gamma \delta$ T cells in the LNs of IL-1 $\beta$-deficient mice, and the effect of TLR2 was intrinsic to MyD88 signaling on T cells, as Lck-cre $\times M y D 88^{\mathrm{f} / \mathrm{ll}}$ mice did not develop protection against $2^{\circ} \mathrm{S}$. aureus skin infection. TLR2 was likely activated by known
S. aureus-derived ligands for TLR2 (e.g., lipoproteins/lipopeptides, LTA, and PGN; ref. 6) in the infected skin and/or in the draining LNs to generate the protective $\gamma \delta$ T cells that produced TNF/IFN- $\gamma$ rather than IL-17A. This is consistent with the lack of expansion of IL-17A-producing $\gamma \delta \mathrm{T}$ cells in IL-1 $1 \beta^{-/-}$mice after the $1^{\circ} S$. aureus skin infection in vivo despite active TLR2/MyD88 signaling in these mice. Although a prior report found that TLR2 activation of $\gamma \delta$ T cells in vitro resulted in IL-17A production, IL-1 $\beta$ was likely also produced in the cultures, providing an alternative explanation for the increased IL-17A production (41).

Regarding the specific CDR3 gene rearrangements, our results greatly modify the currently accepted views on $\gamma \delta$ T cells. Early seminal discoveries demonstrated that the first murine $\gamma \delta \mathrm{T}$ cells produced by the thymus during early development have canonical TCRs lacking $\mathrm{N}$ additions, including an invariant $\delta$ chain $(43,44)$. It is believed that these $\mathrm{T}$ cells then migrate to distinctive sites within the body dictated by the TCR- $\gamma$ chain they express $(33,45)$. The TRGV5 gene rearrangement detected in our study corresponds to that reported for the previously described invariant $\mathrm{V} \gamma 5^{+}$dendritic epidermal T cells (DETCs) $(43,44)$. DETCs are the most common skin-resident $\gamma \delta \mathrm{T}$ cell population and have been reported to recognize a stress-induced self-antigen derived from keratinocytes $(46,47)$. In contrast, the TRGV6 gene rearrangement described herein corresponds to that reported for canonical $\gamma \delta$ T cells residing in the liver, placenta, kidney, uterus, tongue and other mucosal sites $(33,45)$. Interestingly, the dominant TRDV4 gene rearrangement that was found in both the skin and LNs encodes the same CDR3 aa sequence for the V $\delta 1$ chain of DETCs and was previously reported to only be present in remodeling epithelial tissues such as the placenta and lactating mammary glands $(48,49)$. Although still the dominant view, some reports have been inconsistent with the distribution of $\gamma \delta$ T cells just described. For example, a recent

\section{Table 4. Analysis of TRD CDR3 V-D-J junction}

\begin{tabular}{|c|c|c|c|c|c|c|c|c|}
\hline V name & 3'V region & $\mathbf{N}$ & $\mathbf{P}$ & D region & $\mathbf{P}$ & $5^{\prime}$ J region & J name & D name \\
\hline TRDV4*01 & TGTGGGTCAGATATC & & & $\ldots$. GGA & G & СТCCTGGGACACCCGACAGATGTTTTTT & $\operatorname{TRD} \mid 2^{*} 01$ & $\operatorname{TRDD2}{ }^{*} 01$ \\
\hline
\end{tabular}

TRDV4 nt sequences of $3^{\prime} \mathrm{V}$ region and $5^{\prime}$ J region from the top TRD-encoded CDR3 aa sequence in Figure 8B. Germline residues not depicted are shown as periods (each individual period indicates a single unincorporated germline nucleotide). Bold indicates nt differences. 
Table 5. Correlation of CDR3 sequences and T cell transcription factors

$\begin{array}{lcccc}\text { Gene } & \text { Spearman TRDV4 } & \boldsymbol{P} \text { value } & \text { Spearman TRGV5/TRGV6 } & \boldsymbol{P} \text { value } \\ \text { TBX21 } & \mathbf{0 . 5 7} & \mathbf{6 . 0 2 \times \mathbf { 1 0 }} \mathbf{1 0}^{-03} & \mathbf{0 . 6 2} & \mathbf{2 . 2 4 \times \mathbf { 1 0 }} \text {-03 } \\ \text { RORC } & 0.06 & 7.84 \times 10^{-01} & 0.08 & 7.24 \times 10^{-01} \\ \text { CATA3 } & -0.31 & 1.58 \times 10^{-01} & -0.45 & 3.69 \times 10^{-02} \\ \text { FOXP3 } & -0.01 & 9.74 \times 10^{-01} & -0.06 & 7.97 \times 10^{-01}\end{array}$

Spearman correlations between reads mapping to $T$ cell transcription factors and reads mapping to the CDR3-encoding nt sequences of the dominant TRG- and $T R D$-encoded CDR3 aa sequences identified in Figure 8B. Bold indicates a positive correlation between CDR3-encoding transcripts and TBX21 expression. The other factors listed here negatively correlate with CDR3-encoding sequences.

report failed to identify invariant $\mathrm{V} \gamma 5^{+} \gamma \delta \mathrm{T}$ cells in the mouse skin, but rather described an IL-17-producing $\mathrm{CD} 3^{\mathrm{hi}}$ invariant $\mathrm{V} \gamma 6^{+} \gamma \delta$ $\mathrm{T}$ cell population that was increased following imiquimod-induced skin inflammation (50). $\mathrm{V} \gamma 6^{+} \gamma \delta \mathrm{T}$ cells have also been shown to strongly produce IL-17 in response to fungal and bacterial infections, including repeated intraperitoneal exposure to $S$. aureus, at different anatomical sites (32, 51-53).

Our study differs substantially from these prior reports in that we used deep sequencing to characterize the $\gamma \delta \mathrm{T}$ cell repertoire. This revealed that invariant $\mathrm{V} \gamma 5^{+}$and $\mathrm{V} \gamma 6^{+} \mathrm{T}$ cells reside in the skin and in the skin-draining LNs. Furthermore, we demonstrate that both the classical TRGV5 and TRGV6 gene rearrangements encode for the exact same CDR3 aa sequence, CACWDSSGFHKVF, which we found is also encoded by noncanonical TRG gene rearrangements containing $\mathrm{N}$ additions. Finally, we demonstrate that following $S$. aureus skin infection, there is a clonotypic expansion of these TRGV5/V6 $\gamma \delta \mathrm{T}$ cells in the skin-draining LNs. Multiple gene rearrangements encoding for the same $\mathrm{CDR} 3$ aa sequence, as reported here, favor antigen specificity as the driving force behind the observed pathogen-induced $\mathrm{T}$ cell expansion. Although it is unclear whether the $\gamma \delta \mathrm{T}$ cell TCR reactivity was against a yet-tobe-described $S$. aureus-derived antigen or self-antigen as previously postulated $(46,47)$, it is clear that this distinctive TRGV5/ V6-encoded CDR3 aa sequence is critical for mediating robust immune protection against pathogens at the skin and potentially other barrier sites. Furthermore, the TRGV5 and TRGV6 CDR3encoding sequences correlated with $T B X 21$ expression, providing an explanation for increased $\gamma \delta \mathrm{T}$ cell production of TNF/IFN- $\gamma$. The TRGV5/V6 response is in contrast to that observed for TRGV4 $\gamma \delta \mathrm{T}$ cells, which did not expand in response to $S$. aureus infection. $T R G V 4 \gamma \delta \mathrm{T}$ cells were also found at a much lower frequency than the clonotypic TRGV5/V6 $\gamma \delta$ T cells.

In humans, $\mathrm{V} \delta 2^{+} \gamma \delta \mathrm{T}$ cells have a semi-invariant TCR repertoire and rapidly expand and contribute to host defense against microbial infections $(54,55) . \mathrm{V} \delta 1^{+} \gamma \delta \mathrm{T}$ cells have a more diverse TCR repertoire and have been associated with adaptive responses, especially against viruses such as CMV $(54,55)$. In the present study, an increased proportion of circulating TNF/IFN- $\gamma$-producing $\mathrm{V} \delta 2^{+} \gamma \delta$ $\mathrm{T}$ cells were found in IRAK4-deficient individuals; these most likely expanded as a result of the recurrent infections in these patients (8). In the setting of IRAK4 deficiency, the $\mathrm{V} \delta 2^{+} \gamma \delta \mathrm{T}$ cells might restore the impaired neutrophil recruitment response (7), which would explain the patients' decreased susceptibility to $S$. aureus with age $(8,19)$. In contrast, $\mathrm{V} \delta 2^{+} \gamma \delta \mathrm{T}$ cells were virtually absent in individuals with CGD, a disease in which patients never overcome their predisposition to $S$. aureus and other pyogenic infections (37). In addition, almost all of the circulating $\mathrm{V} \delta 1^{+}$and $\mathrm{V} \delta 2^{+} \gamma \delta \mathrm{T}$ cells from all healthy humans and IRAK4 and CGD patients lacked the ability to produce IL-17 (or IL-22). This is in contrast to the high numbers of circulating IL-17-producing $\mathrm{T}$ cells in mice (56), suggesting that IL-17 responses might not be as relevant for circulating $\gamma \delta \mathrm{T}$ cells in humans. Moreover, since human circulating $\gamma \delta \mathrm{T}$ cells primarily produce TNF/IFN- $\gamma$ rather than IL-17 or IL-22, the protective TNF/IFN- $\gamma$-producing $\gamma \delta$ $\mathrm{T}$ cells that we identified in mice might better translate to protective $\gamma \delta$ T cell responses in humans.

There are several limitations and future directions. First, a key question is whether the expanded $\gamma \delta \mathrm{T}$ cells from previously infected $\mathrm{IL}-1 \beta^{-/-}$mice could confer protection to WT mice. To evaluate this, we performed an LN transfer from d 28 $\mathrm{IL}-1 \beta^{--}$mice to naive WT mice as in Figure $4 \mathrm{H}$. However, this did not result in further protection of the WT mice (see Supplemental Figure 6). The lack of protection could have been due to normal IL-1 $\beta$ activity in WT mice, which induced effective neutrophil recruitment that could not be further enhanced. Alternatively, the presence of IL-1 $\beta$ activity could have negatively affected TNF and IFN- $\gamma$ production by the transferred $\gamma \delta \mathrm{T}$ cells from IL-1 $\beta^{-/-}$ mice. A future direction will be to determine the mechanisms by which clonally expanded $\gamma \delta \mathrm{T}$ cells confer protection to WT mice. Second, transfer of $\mathrm{CD} 4^{+} \mathrm{T}$ cells to naive $\mathrm{IL}^{-1} \beta^{-/-}$mice did not have a protective effect. Further, transferring $\gamma \delta$ and $C D 4^{+}$ $\mathrm{T}$ cells in combination resulted in loss of the protective effect of the $\gamma \delta \mathrm{T}$ cells. Although the reason for this is unclear, this result is consistent with recent findings that naturally generated or vaccine-induced $\mathrm{CD}^{+} \mathrm{T}$ cell responses were either not protective or resulted in increased mortality in mouse models of $S$. aureus bacteremia $(57,58)$. Third, the FTY720 experiments indicate that trafficking of the protective $\gamma \delta \mathrm{T}$ cells from LNs during the infection was required for protection, but it is unclear whether these cells might also function as tissue-resident cells. Regarding expression of homing and adhesion molecules of tissue-resident memory $\mathrm{T}$ cells, the $\gamma \delta \mathrm{T}$ cells from LNs of $\mathrm{d} 28 \mathrm{IL}-1 \beta^{-/-}$mice had substantially decreased expression of CCR 4 and significant but subtle differences in expression of CD103 and CLA compared with that in naive IL-1 $\beta^{-/-}$mice (Supplemental Figure 7). Finally, it is unclear whether the TCR signaling in the $\gamma \delta \mathrm{T}$ cells was required for protection; however, the butyrophilin family members (e.g., Skint1, Skint3, or Skint9) have recently been implicated as TCR ligands or costimulatory molecules for DETCs, which express the same CDR3 aa sequence $(59,60)$. There was a significant correlation between reads encoding for the top $\gamma \delta$ CDR3 sequences and BTLN2 (but not SKINT1, SKINT3, or SKINT9) in the LNs of d28 IL-1 $\beta$ mice (Supplemental Figure 8), suggesting that Btnl2 might activate the protective $\gamma \delta \mathrm{T}$ cells in our model. A role of TCR signaling and butyrophilin family members will be the subject of our future work.

Taken together, this study identified a clonotypic expansion of TNF/IFN- $\gamma$-producing $\gamma \delta$ T cells that were induced by TLR2/ MyD88 signaling to promote protection against an S. aureus 
A

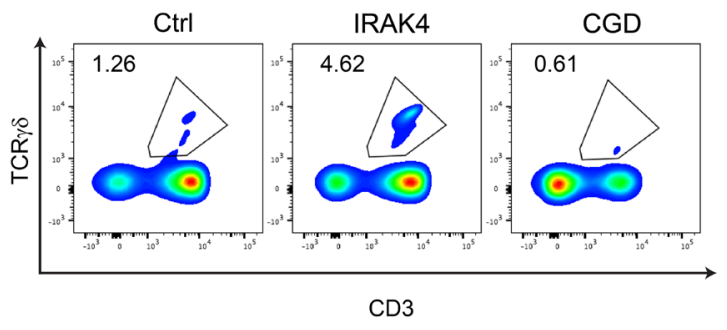

C

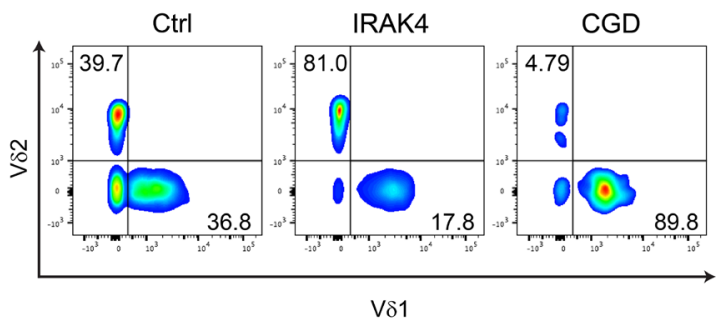

E $\mathrm{TNF}^{+} \gamma \delta \mathrm{T}$ cells

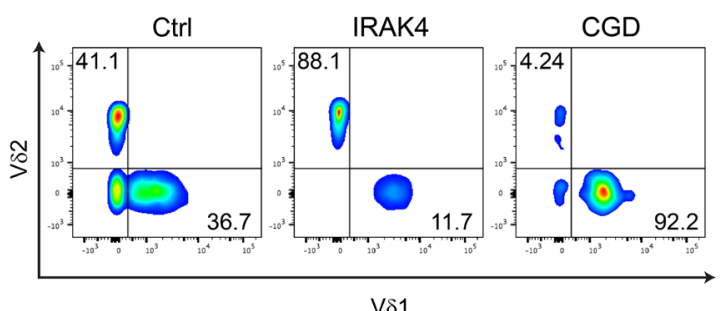

G IFN $-\gamma^{+} \gamma \delta T$ cells

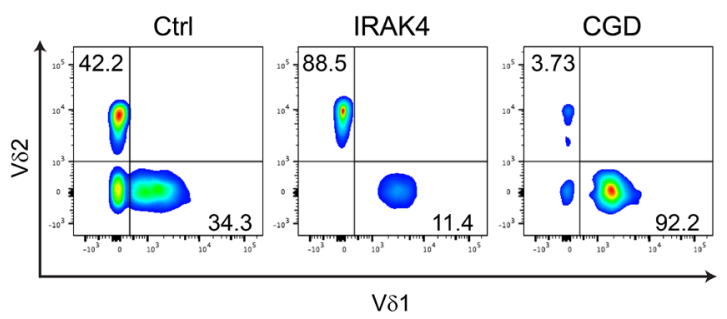

I IL-17A $\mathrm{CD}^{+} \mathrm{T}$ cells

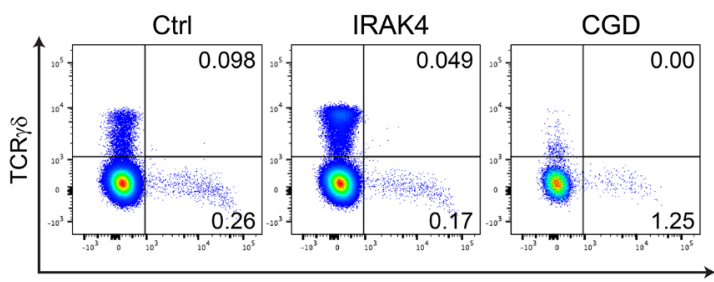

IL-17A
B $\%{\mathrm{TCR} \gamma \delta^{+}}^{+}$

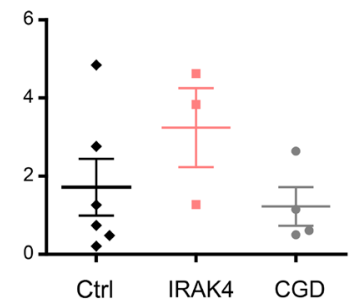

D $\% \mathrm{~V} \delta 1^{+}$versus $\mathrm{V} \delta 2^{+}$

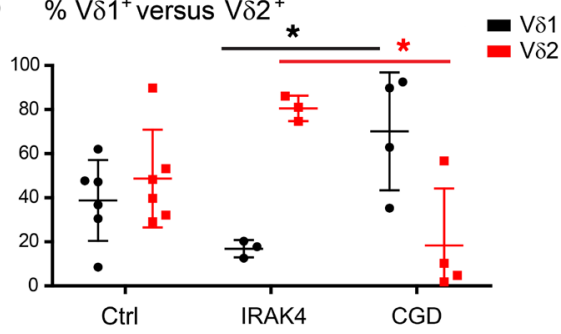

F $\% \mathrm{TNF}^{+} \gamma \delta \mathrm{T}$ cells

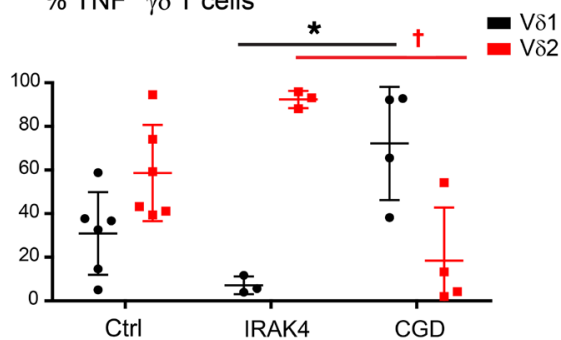

H $\%$ IFN- $\gamma^{+} \gamma \delta$ T cells

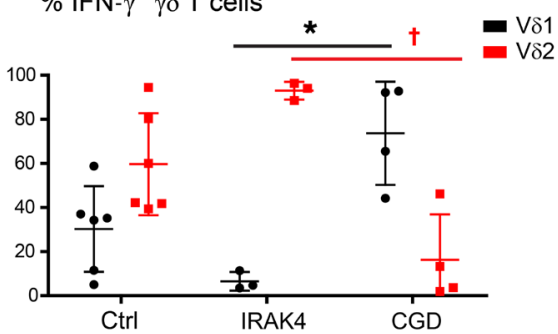

J $\% \mathrm{IL}-17 \mathrm{~A}^{+} \mathrm{CD}^{+} \mathrm{T}$ cells

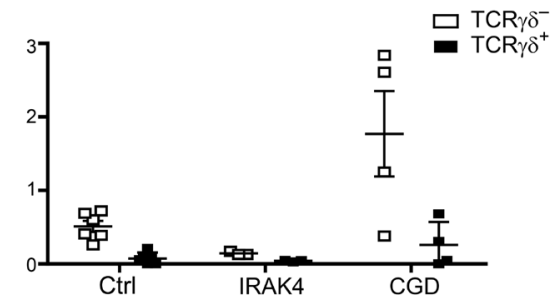

Figure 9. TNF/IFN- $\gamma$-producing $\gamma \delta$ T cells from PBMCs in individuals with IRAK4 deficiency and CCD. PBMCs from healthy controls (ctrl, $n=6$ ), patients with IRAK4 deficiency ( $n=3$ samples, including 2 samples from the same individual at age 17, toward the end of the predilection for recurrent infection, and at age 22), and patients with CGD $(n=4)$ were analyzed. Representative flow plots and mean percentage \pm SEM are shown for total $\gamma \delta$ T cells in PBMCs $(\mathbf{A}$ and $\mathbf{B}), V \delta 1^{+}$versus $V \delta 2^{+} \gamma \delta$ T cells $(\mathbf{C}$ and $\mathbf{D})$, TNF production (E and $\mathbf{F}$ ), IFN- $\gamma$ production $(\mathbf{G}$ and $\mathbf{H})$, and IL-17A production $(\mathbf{I}$ and $\mathbf{J})$. ${ }^{*} P<0.05 ;{ }^{\dagger} P<0.01$, as measured by 2-tailed Student's $t$ test with Bonferroni's correction.

skin reinfection. These findings provide important mechanistic insights for targeting specific $\gamma \delta \mathrm{T}$ cells in future vaccines and immunotherapies to promote durable immunity against S. aureus skin infections.

\section{Methods}

Staphylococcus aureus strain. The bioluminescent USA300 LAC::lux strain used in all experiments was previously generated from the community-acquired methicillin-resistant S. aureus (MRSA) USA300 
LAC isolate obtained from a skin infection outbreak in the Los Angeles County Jail (Los Angeles, California, USA) and was provided by Tammy Kielian (University of Nebraska, Lincoln, Nebraska, USA). USA300 LAC::lux possesses a modified luxABCDE operon stably integrated in the bacterial chromosome so that the emission of blue-green light from live and metabolically active bacteria is maintained in all progeny without selection.

Bacterial preparation. S. aureus bacteria was streaked onto a tryptic soy agar (TSA) plate (tryptic soy broth [TSB] plus 1.5\% bacto agar; $\mathrm{BD}$ Biosciences) and grown overnight at $37^{\circ} \mathrm{C}$ in a bacterial incubator. Single colonies were cultured in TSB at $37^{\circ} \mathrm{C}$ in a shaking incubator (240 rpm) overnight (18 hours), followed by a $1: 50$ subculture at $37^{\circ} \mathrm{C}$ for 2 hours to obtain midlogarithmic phase bacteria. The bacteria were pelleted, resuspended, and washed in PBS. The absorbance $\left(\mathrm{A}_{600}\right)$ was measured to estimate the number of CFUs, which was verified after overnight culture on TSA plates.

Mice. C57BL/6 WT mice, TLR2 ${ }^{-/-}$mice (B6.129-Tlr2 $\left.2^{\text {tmlKir }} / \mathrm{J}\right)$, Lckcre mice (B6.Cg-Tg(Lck-cre)548Jxm/J), and MyD88 ${ }^{\mathrm{fl} / \mathrm{ll}}$ (B6.129P2(S$\left.\mathrm{JL})-\mathrm{MyD} 88^{\mathrm{tm} 1 \mathrm{Defr}} / \mathrm{J}\right)$ mice were obtained from Jackson Laboratories. Lck-cre mice were crossed with MyD88 $8^{\mathrm{t} / \mathrm{fl}}$ mice to obtain the Lck-cre $\times$

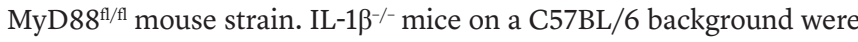
provided by Yoichiro Iwakura (University of Tokyo, Tokyo, Japan).

Mouse model of $S$. aureus skin reinfection. For each experiment, sex- and age-matched mice were used beginning at 6 and 8 weeks of age. For the $1^{\circ} S$. aureus skin infection, the dorsal backs of anesthetized mice ( $2 \%$ isoflurane) were shaved and injected intradermally (i.d.) in the lower back with $3 \times 10^{7}$ CFU of USA300 LAC::lux in $100 \mu \mathrm{l}$ of PBS using a 29-gauge insulin syringe. After a 2-week convalescent period, on $\mathrm{d} 28$, a $2^{\circ} \mathrm{S}$. aureus skin infection was performed by i.d. injection at a distant skin site in the upper back with the same inoculum and procedures as used for the $1^{\circ} \mathrm{S}$. aureus skin infection. In some experiments, the convalescent period was increased to 8 or 20 weeks prior to the $2^{\circ}$ S. aureus skin infection or the i.d. inoculation sites on the lower and upper backs of mice were reversed.

Measurement of total lesion area. Total lesion size $\left(\mathrm{cm}^{2}\right)$ was measured from digital photographs of the skin of anesthetized mice (2\% isoflurane) using ImageJ software (NIH) and a millimeter ruler as a reference.

In vivo bioluminescent imaging. In vivo bioluminescent imaging was performed on anesthetized mice ( $2 \%$ isoflurane) using a Lumina III IVIS (PerkinElmer) and total flux (photons/s) was measured within a $1 \times 10^{3}$ pixel circular region of interest using Living Image software (PerkinElmer) (limit of detection: $2 \times 10^{4}$ photons/s).

Skin tissue homogenates and bacterial quantification. Skin tissue homogenates were obtained by performing a 10-millimeter lesional skin punch biopsy (Acuderm) and homogenizing each specimen (Pro200 Series homogenizer; Pro Scientific) in Reporter Lysis buffer (Promega) containing protease inhibitor cocktail tablets (Roche Life Sciences) at $4^{\circ} \mathrm{C}$. Ex vivo CFUs were counted after plating serially diluted skin tissue homogenates overnight on TSA plates.

Histology. Skin punch biopsy specimens $(10 \mathrm{~mm})$ were collected, fixed in formalin (10\%), and embedded in paraffin. Sections $(4 \mu \mathrm{m})$ were mounted onto glass slides and stained with $\mathrm{H} \& \mathrm{E}$ and Gram stain by the Johns Hopkins Reference Histology Laboratory.

Measurement of total and S. aureus-specific IgG. Levels of total IgG in serum and skin tissue homogenates were determined using a mouse IgG ELISA according to the manufacturer's protocol (eBioscience). S. aureus-specific IgG levels in the specimens were obtained by coating ELISA plates overnight with heat-killed USA300 LAC::lux in the stationary phase and then proceeding with manufacturer's instructions (eBioscience).

Serum isolation and transfer to mice. Mouse serum was obtained from newly collected blood (from terminal cardiac puncture on anesthetized mice), which was allowed to clot at room temperature for 30 minutes. Serum supernatants were then collected after centrifuging the clotted blood at $1,500 \mathrm{~g}$ for 10 minutes at $4^{\circ} \mathrm{C}$. Serum samples were stored at $-20^{\circ} \mathrm{C}$ prior to use. Serum $\left(200 \mu \mathrm{l}, 37^{\circ} \mathrm{C}\right)$ was transferred to mice via i.v. injection (via retroorbital vein) on day -1 (d-1) and do prior to $S$. aureus skin inoculation; serum used was 4 times that transferred in a prior study (18).

In vivo antibody and FTY administration. For $\mathrm{CD}^{+} \mathrm{T}$ cell depletion, mice were treated i.p. with anti-CD4 antibody (clone GK1.5, BioXCell) $300 \mu \mathrm{g}$ in $500 \mu \mathrm{l} \mathrm{PBS}$ on $\mathrm{d}-1$ and $100 \mu \mathrm{g}$ in $500 \mu \mathrm{l}$ sterile PBS on d0 and $\mathrm{d} 7$ of the $2^{\circ} \mathrm{S}$. aureus skin infection, according to previously described dosing (18). Depletion of $\mathrm{CD} 4^{+} \mathrm{T}$ cells was confirmed from blood samples (collected via retroorbital venipuncture) immediately prior to the S. aureus skin infection by flow cytometry using antibodies against CD4 (clone RM4-5), CD8 $\alpha$ (clone 53-6.7), and CD3ع (clone 145-2C11). For combined TNF and IFN- $\gamma$ neutralization, mice were treated i.p. with anti-mouse TNF (clone XT3.11) and anti-mouse IFN- $\gamma$ (clone XMG 1.2), with $200 \mu$ g of each given together in $500 \mu$ sterile PBS on $\mathrm{d}-1, \mathrm{~d} 0$, and $\mathrm{d} 1$ of the $2^{\circ} \mathrm{S}$. aureus skin infection, according to the manufacturer's recommended dosing (BioXCell). To block IL-1R1, mice were treated i.p. with anti-IL-1R1 antibody (clone JAMA-147) $100 \mu \mathrm{g}$ in $500 \mu \mathrm{l}$ sterile PBS beginning on $\mathrm{d}-1, \mathrm{~d} 0$, and $\mathrm{d} 1$ of the $1^{\circ} S$. aureus skin infection and then every other day throughout the entire 42-day experiment (including during the $2^{\circ} \mathrm{S}$. aureus skin infection), according to the manufacturer's recommended dosing (BioXCell). All control mice were treated i.p. with a corresponding isotype control antibody (BioXCell) at the equivalent dose and volume. To block lymphocyte efflux from LNs, mice were treated i.p. with FTY720 (Sigma-Aldrich), $1 \mathrm{mg} / \mathrm{kg}$ in $100 \mu \mathrm{l}$ sterile water, beginning on $\mathrm{d} 27, \mathrm{~d} 28$, and $\mathrm{d} 29$ of the $2^{\circ}$ S. aureus skin infection and continuing every other day as previously described (24).

Lymphocyte isolation, magnetic bead separation, and transfer to mice. A single suspension of LN cells was obtained after manually pushing draining LNs through a cell-separation filter $(40 \mu \mathrm{m})$. Cells were counted and resuspended in MACS Separation Buffer (degassed PBS containing BSA [0.5\%] and EDTA [2 mM]) (Miltenyi Biotec). $\gamma \delta$ T cells were isolated using a TCR $\gamma / \delta^{+}$Isolation Kit for mice, according to the manufacturer's instructions (Miltenyi Biotec). Briefly, non-T cells were depleted using direct magnetic labeling of CD45R and CD11b microbeads. Next, $\gamma \delta \mathrm{T}$ cells were indirectly labeled using anti-TCR $\gamma / \delta$-biotin, and anti-biotin microbeads were then used to positively select $\gamma \delta \mathrm{T}$ cells. The remaining $\mathrm{T}$ cells were collected via flow-through on the column. 50,000 $\gamma \delta$ T cells or 5 million $\mathrm{CD}^{+} \mathrm{T}$ cells (devoid of $\gamma \delta \mathrm{T}$ cells) in the flow-through were transferred to mice i.v. (via retroorbital vein) at 1 day prior to $S$. aureus skin inoculation. The adoptively transferred cells were either $96.1 \% \mathrm{CD}^{+} \mathrm{T}$ cells with $0.8 \% \mathrm{GL}^{+} \gamma \delta \mathrm{T}$ cells collected from the flow-through or $95.7 \% \mathrm{GL}^{+}$ $\gamma \delta \mathrm{T}$ cells isolated from the column (Supplemental Figure 5). In a separate experiment, $\gamma \delta$ T cells were isolated as described above, while the non-T cell-depleted fraction left over after this isolation was subsequently used to isolate $\mathrm{CD} 4^{+} \mathrm{T}$ cells using a $\mathrm{CD} 4^{+} \mathrm{T}$ cell isolation kit (Miltenyi Biotech) per the manufacturer's instructions. One day prior to inoculation with S. aureus, 50,000 $\gamma \delta$ T cells, 5 million $\mathrm{CD}^{+}{ }^{+} \mathrm{T}$ cells, or 50,000 $\gamma \delta$ T cells plus 5 million $\mathrm{CD}^{+} \mathrm{T}$ cells were injected via retroorbital vein. The purity 
percentages of isolated cells that were adoptively transferred were $95.7 \%$ $\mathrm{GL}^{+} \gamma \delta \mathrm{T}$ cells and $98.1 \% \mathrm{CD} 4^{+} \mathrm{T}$ cells (Supplemental Figure 5).

Mouse cell phenotypic analysis. LNs were harvested from mice, and single-cell suspensions were created. Cells were resuspended in PBS containing 1\% BSA. $1 \times 10^{6}$ Cells were stained for surface markers using antibodies against CCR4 (clone 2G12), CD4 (clone GK1.5), CD8 $\alpha$ (clone 53-6.7), CD3 (clone REA641), CLA (HECA-452), TCR $\gamma \delta$ (clone GL3), CD103 (clone REA789), and TLR2 (clone 6C2) for 30 minutes at $4^{\circ} \mathrm{C}$. Cells were washed twice in PBS and resuspended in PBS with $1 \%$ BSA for acquisition. Propidium iodide was added at 1:100 immediately prior to acquisition for discrimination of dead cells. Intracellular staining was performed by first creating single-cell suspensions from LNs, which were resuspended in RPMI containing FBS (10\%), penicillin $(100 \mathrm{U} / \mathrm{ml})$, and streptomycin $(100 \mu \mathrm{g} / \mathrm{ml}) .1 \times 10^{6}$ Cells per well were plated in 96-well cell-culture plates in the presence of a cell-stimulation cocktail plus protein transport inhibitors (eBioscience) containing PMA, ionomycin, brefeldin A, and monensin. Control wells contained only protein transport inhibitor cocktail (brefeldin A and monensin). Cells were incubated at $37^{\circ} \mathrm{C}$ for 6 hours. Cells were washed once before staining for viability (Viability Fixable Dye, Miltenyi Biotec) and surface markers using antibodies against CD4 (clone RM4-5), CD8 $\alpha$ (clone 53-6.7), and TCR $\gamma \delta$ (clone GL3) for 30 minutes at $4^{\circ} \mathrm{C}$. Cells were washed before being fixed using FACSFix (BD Biosciences) for 30 minutes. Cells were permeabilized by washing 3 times and then incubating for 10 minutes in Perm/Wash (BD Biosciences) and then incubated with antibodies against IL-17A (clone TC11-18H10), IL-22 (clone IL22JOP), TNF (clone MP6-XT22), and IFN- $\gamma$ (clone XMG1.2) or isotype control mAbs (Miltenyi Biotec) (Supplemental Figure 9) for 30 minutes before being washed and resuspended. Cell acquisition was performed on a MACSQuant flow cytometer (Miltenyi Biotec), and data were analyzed using FlowJo software (Tree Star).

Cytokine protein levels. Protein levels of IL-22, IFN- $\gamma$, and TNF were measured from homogenized punch biopsy specimens collected at $\mathrm{d} 1$ after the $S$. aureus skin inoculation by using Bio-Plex protein assays and normalized to total protein according to the manufacturer's recommendations (Bio-Rad). Protein levels of IL-17A were measured using an ELISA kit according to the manufacturer's recommendations (R\&D Systems). Data are presented as pg/ml (Bio-Plex) or pg/mg tissue weight (ELISA).

RNA isolation. Mouse LNs and skin biopsies were stabilized by addition of RNAlater (Ambion). Homogenization was performed using a TissueLyzer II (QIAGEN) at $20 \mathrm{~Hz}$ for 1 minute at $-80 \mathrm{C}$. Total RNA was extracted using the RNeasy Plus Mini Kit (QIAGEN). RNA concentrations were then quantified using a Qubit Fluorometer, and RNA integrity was assessed using the Agilent TapeStation (Agilent). Samples with RNA integrity number (RIN) of 8 or more were used for this study.

RNA-seq. Indexed libraries were constructed from 1,000 ng of total RNA using the TruSeq Stranded mRNA Sample Prep Kit (Illumina) following the manufacturer's instruction. The quantity and quality of the libraries were also assessed by Qubit and Agilent 2100 Bioanalyzer, respectively. The average library size was $400 \mathrm{bp}$. Library molar concentration was validated by quantitative PCR (qPCR) for library pooling. Sequencing was performed on the Illumina HiSeq 4000 platform using PE150 chemistry (Illumina). RNA-seq data were deposited in the NCBI's Sequence Read Archive database (SRA SRP126124).

Analysis of public data sets. RNA-seq FASTQ files of mouse skin were downloaded from the NCBI SRA database (SRA SRP040121), and information about the samples is in the corresponding publication (36).
RNA-seq data analysis. Raw sequencing data were received in FASTQ format. Sequencing reads were mapped to the UCSC mm10 mouse reference genome by STAR. Gene-expression level normalization and differential expression analysis were carried out by using the DESeq2 Bioconductor R package. This package provides statistics for determination of differential expression using a model based on the negative binomial distribution. Genes with an adjusted $P$ value of less than 0.05 and fold change greater than 2 were assigned as differentially expressed. In order to examine the relationship of gene expressions across the samples, Spearman's correlation of normalized gene counts was computed. Spearman's rank correlation coefficients and $P$ values were calculated in R (version 3.1.2, http://www.R-project.org/) using the cor.test function.

Extraction of TCR sequence information from RNA-seq data. MiXCR software was used to extract TCR CDR3 sequences from RNA-seq data. Analyses were performed with the "-p rna-seq" option recommended for analysis of RNA-seq data.

CDR3 definition. The TCR CDR3 region was defined as the amino acid residues starting with the $C$ at position 104 and ending with the $\mathrm{F}$ at position 118 based on International ImMunoGeneTics (IMGT) nomenclature and a TCR numbering system. Likewise, gene names of $\mathrm{V}$ and $\mathrm{J}$ regions are designated according to the IMGT name nomenclature for $\mathrm{T}$ cell receptors of mice.

Amplification of TCR CDR3. For targeted CDR3 sequencing, we synthesized cDNA with anchor sequence incorporation. This method is based on the $5^{\prime}$ template-switching ability of certain reverse transcriptases, which has been used for $\alpha \beta \mathrm{T}$ cell repertoire analysis (61). Reverse transcriptions were performed using the Ribo_TSO (5'-AAGCAGTGGTATCAACGCAGAGTACTCTT( $\left.(\mathrm{rG})_{5}-3^{\prime}\right)$, TCR $\mathrm{C} \gamma$ - and $\mathrm{C} \delta$-specific primers mDC1R RT (5'-CACCAGACAAGCAACATTTG-3'), mGC1R RT (5'-CTTTTCTTTCCAATACACCCTTAT-3'), and SMARTScribe reverse transcriptases (Clontech) according to the manufacturer's instructions. Quantitative real-time PCR (qRT-PCR) was performed for each sample to identify the minimum number of PCR cycles needed to ideally amplify TCR without overamplification. We carried out qRT-PCR iProof High-Fidelity Master Mix (Bio-Rad) and EvaGreen Dye (Biotium) with the following primer pairs: Smart20 (5'-CACTCTATCCGACAAGCAGTGGTATCAACGCAG-3'), mDC2R (5'-CATGATGAAAACAGATGGTTTGG-3') for TCR $\delta$, Smart20 (5'-CACTCTATCCGACAAGCAGTGGTATCAACGCAG-3'), and mGC2R (5'-GGAGATTTGTTTCAGCA-3') for TCR- $\gamma$. The PCR cycle was as follows: $98^{\circ} \mathrm{C}$ for 2 minutes, $95^{\circ} \mathrm{C}$ for 20 seconds, $68^{\circ} \mathrm{C}$ for 20 seconds, and $72^{\circ} \mathrm{C}$ for 50 seconds for 40 cycles, followed by a final extension step of $72^{\circ} \mathrm{C}$ for 5 minutes. Once the optimal number of PCR cycles was established, final PCR was carried without EvaGreen. All amplification reactions were assayed in at least 10 separate tubes to minimize PCR amplification bias. The reaction products were purified using the MinElute PCR Purification Kit using Qiacube (QIAGEN) and quantified using a Qubit Fluorometer and Quant-iT dsDNA BR Assay Kit (Invitrogen).

TCR library preparation. All libraries from purified TCR amplicons were prepared using the Nextera XT Index Kit (Illumina Inc.) according to the manufacturer's instructions for the 16S Metagenomic Sequencing Library Preparation protocol, with minor modifications. Briefly, first-stage PCR was performed with KAPA HiFi HotStart ReadyMix (KAPA Biosystems) and the primer pairs were designed according to protocol guidelines. Primer pairs were as follows: firststage PCR forward primer: Nextera-Step_1: 5'-TCGTCGGCAGCGTCAGATGTGTATAAGAGACAGCACTCTATCCGACAAGCAGT-3'; 
first-stage PCR reverse primer for TCR $\delta$ NextMusDCj: 5'-GTCTCGTGGGCTCGGAGATGTGTATAAGAGACAGTTTGGCCGGAGGCTGGCTTT-3'; and first-stage PCR reverse primer for TCR- $\gamma$ NextMusDG2R: 5'-GTCTCGTGGGCTCGGAGATGTGTATAAGAGACAGGAGATTTGTTTCAGCA-3'. First-stage PCRs were purified using AMPure XP beads (Beckman Coulter Inc).

Illumina sequencing adapters and dual index barcodes were added in subsequent second-stage PCR using the Nextera XT indices and HotStart ReadyMix (KAPA Biosystems).

Indexed libraries were purified using 2 rounds of 0.7 volumes of AMPure XP beads (Beckman Coulter Inc.) and quantified using a Qubit Fluorometer and Quant-iT HS DNA Assay Kit (Invitrogen). The quality of the libraries was also assessed by Agilent 2100 Bioanalyzer, and the average library size was 600-700 bp.

TCR library sequencing and analysis. Libraries were pooled to a final pool concentration of $4 \mathrm{nM}$ including a 10\% PhiX Control v3 (Illumina) spike-in. Sequencing was performed on an Illumina MiSeq sequencer using the 600-cycle MiSeq Reagent Kit v3 (Illumina) with paired-end reads. Raw-sequencing reads were processed for FASTQ conversion and demultiplexing using the MiSeq Reporter. MiXCR software was used to extract TCR CDR3 sequences from sequencing data. All gene names used are according to IMGT nomenclature. Data visualization and TCR repertoire comparison were done in $\mathrm{R}$ (version 3.1.2). The IMGT/Junction Analysis tool was used to analyze in detail the CDR3 V-D-J and V-J junctions.

Human cell phenotypic analysis. Peripheral blood mononuclear cells (PBMCs) were isolated by density centrifugation and resuspended in RPMI 1640 supplemented with penicillin, streptomycin, and L-glutamine along with $10 \%$ fetal calf serum. PBMCs rested for 1 hour in the media at $37^{\circ} \mathrm{C}$. Subsequently, cells were costimulated with PMA and ionomycin (Calbiochem) plus brefeldin A (Sigma-Aldrich). Cells were incubated for 5 hours at $37^{\circ} \mathrm{C}$. Following incubation, PBMCs were washed in PBS containing $0.5 \%$ BSA and stained for extracellular markers including Live/Dead Fixable Blue Viability Dye (Invitrogen); CD3 (clone UCHT1), CD27 (clone L128) (both BD Biosciences); CD4 (clone RPA-T4, BioLegend); CD45RO (clone UCHL1, Beckman Coulter); TCR $\gamma \delta$ (clone

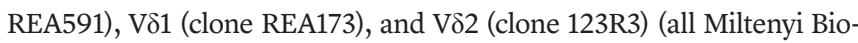
tec). PBMCs were then fixed and permeabilized using BD Biosciences Cytofix/Cytoperm Kit. Finally, PBMCs were stained for intracellular cytokine production of TNF (clone mAb 11 RUO) IFN- $\gamma$ (clone B27) (both BD Biosciences), and IL-17A (clone eBio64CAP17, eBioscience) and analyzed by flow cytometry and using FlowJo software (Tree Star).

Statistics. Statistical analysis of the RNA-seq data is described above. For all other experiments, data for multiple comparisons were compared using 2-way ANOVA, and data from single comparisons were compared using 2-tailed Student's $t$ test. In certain instances, Bonferroni's correction was applied to account for multiple comparisons, as indicated in the figure legends. All statistical analyses were calculated using Prism software (GraphPad). Data are presented as mean \pm SEM, and values of $P<0.05$ were considered to be statistically significant.

Study approval. All mice were bred and maintained under specific pathogen-free conditions at an animal facility accredited by the American Association for the Accreditation of Laboratory Animal Care (AAALAC) at Johns Hopkins and housed according to procedures described in the Guide for the Care and Use of Laboratory Animals (National Academies Press, 2011). All animal studies were approved by the Johns Hopkins University Animal Care and Use Committee. All human subject samples were gathered at the NIH Clinical Center via protocol NCT00001355, approved by the National Institute of Allergy and Infectious Diseases Institutional Review Board. These included healthy human subjects $(n=6)$ and individuals with genetically confirmed IRAK4 deficiency $(n=2)$ or CGD ( $n=4$ individuals). Both individuals with IRAK4 deficiency had a history of recurrent $S$. aureus skin infections, 3 of the 4 individuals with CGD had a history of recurrent $S$. aureus skin infections, and all 4 individuals with CGD had a history of an S. aureus liver abscess. All samples were collected from adults, with the exception of the first of 2 samples from an IRAK4-deficient patient, which were drawn when she was 17 (a sample that was collected toward the end of her predilection for recurrent infection). All patients gave informed consent.

\section{Author contributions}

CAD, BLP, AIM, AAM, ONF, HL, NKA, DBL, YW, RVO, SKL, MCM, SSC, AGA, LS May, LGM, MRY, SIS, JDM, EM, and LS Miller performed experiments and analyzed data. AFF, SMH, and JDM evaluated patients and obtained samples. CAD, AIM, AAM, ONF, LS May, LGM, MRY, SIS, JDM, EM, and LS Miller conceived the study, designed experiments, interpreted data and wrote the manuscript.

\section{Acknowledgments}

This work was supported by grants R01AR069502 (to L.S. Miller), R21AI126896 (to L.S. Miller), 1DP2OD008752 (to EM), U01AI124319 (to MRY), and R01AI129302 (to SIS) and in part by the Division of Intramural Research of the National Institute of Allergy and Infectious Diseases of the US NIH (to SMH, AFF, and JDM) and an early career award from the Burroughs Wellcome Fund (to EM). The content is solely the responsibility of the authors and does not necessarily represent the official views of the US NIH. We thank Tammy Kielian (University of Nebraska) for providing the USA300 LAC::lux strain and Yoichiro Iwakura (University of Tokyo) for generously providing the IL-1 $1 \beta^{-/-}$mice.

Address correspondence to: Lloyd S. Miller, Johns Hopkins Department of Dermatology, Cancer Research Building II, Suite 205, 1550 Orleans Street, Baltimore, Maryland 21231, USA. Phone: 410.955.8662; Email: lloydmiller@jhmi.edu.
1. Tong SY, Davis JS, Eichenberger E, Holland TL, Fowler VG. Staphylococcus aureus infections: epidemiology, pathophysiology, clinical manifestations, and management. Clin Microbiol Rev. 2015;28(3):603-661.

2. Montgomery CP, David MZ, Daum RS. Host factors that contribute to recurrent staphylococcal skin infection. Curr Opin Infect Dis. 2015;28(3):253-258.
3. Holtfreter S, Kolata J, Bröker BM. Towards the immune proteome of Staphylococcus aureus The anti-S. aureus antibody response. Int JMed Microbiol. 2010;300(2-3):176-192.

4. Kolata JB, et al. The fall of a dogma? unexpected high t-cell memory response to Staphylococcus aureus in humans. JInfect Dis. 2015;212(5):830-838.

5. Fowler VG, Proctor RA. Where does a Staphylococcus aureus vaccine stand? Clin Microbiol
Infect. 2014;20 Suppl 5:66-75.

6. Miller LS, Cho JS. Immunity against Staphylococcus aureus cutaneous infections. Nat Rev Immunol. 2011;11(8):505-518.

7. Bouma $\mathrm{G}$, et al. Impaired neutrophil migration and phagocytosis in IRAK-4 deficiency. Br J Haematol. 2009;147(1):153-156.

8. Picard C, et al. Pyogenic bacterial infections in humans with IRAK-4 deficiency. Science. 
2003;299(5615):2076-2079.

9. von Bernuth $\mathrm{H}$, et al. Pyogenic bacterial infections in humans with MyD88 deficiency. Science. 2008;321(5889):691-696.

10. Lévy R, et al. Genetic, immunological, and clinical features of patients with bacterial and fungal infections due to inherited IL-17RA deficiency. Proc Natl Acad Sci U S A. 2016;113(51):E8277-E8285.

11. Milner JD, et al. Impaired T(H)17 cell differentiation in subjects with autosomal dominant hyperIgE syndrome. Nature. 2008;452(7188):773-776.

12. Puel A, et al. Chronic mucocutaneous candidiasis in humans with inborn errors of interleukin-17 immunity. Science. 2011;332(6025):65-68.

13. Cho JS, et al. Neutrophil-derived IL-1 $\beta$ is sufficient for abscess formation in immunity against Staphylococcus aureus in mice. PLoS Pathog. 2012;8(11):e1003047.

14. Miller LS, et al. MyD88 mediates neutrophil recruitment initiated by IL-1R but not TLR 2 activation in immunity against Staphylococcus aureus. Immunity. 2006;24(1):79-91.

15. Chan LC, et al. Nonredundant roles of interleukin-17A (IL-17A) and IL-22 in murine host defense against cutaneous and hematogenous infection due to methicillin-resistant Staphylococcus aureus. Infect Immun. 2015;83(11):4427-4437.

16. Cho JS, et al. IL-17 is essential for host defense against cutaneous Staphylococcus aureus infection in mice. J Clin Invest. 2010;120(5):1762-1773.

17. Gaidamakova EK, et al. Preserving immunogenicity of lethally irradiated viral and bacterial vaccine epitopes using a radio- protective Mn2+-Peptide complex from Deinococcus. Cell Host Microbe. 2012;12(1):117-124.

18. Montgomery CP, Daniels M, Zhao F, Alegre ML, Chong AS, Daum RS. Protective immunity against recurrent Staphylococcus aureus skin infection requires antibody and interleukin-17A. Infect Immun . 2014;82(5):2125-2134.

19. Picard C, et al. Clinical features and outcome of patients with IRAK-4 and MyD88 deficiency. Medicine (Baltimore). 2010;89(6):403-425.

20. Patel DD, Kuchroo VK. Th17 cell pathway in human immunity: lessons from genetics and therapeutic interventions. Immunity. 2015;43(6):1040-1051.

21. Sampedro GR, et al. Targeting Staphylococcus aureus $\alpha$-toxin as a novel approach to reduce severity of recurrent skin and soft-tissue infections. J Infect Dis. 2014;210(7):1012-1018.

22. Tsuda Y, Takahashi H, Kobayashi M, Hanafusa T, Herndon DN, Suzuki F. Three different neutrophil subsets exhibited in mice with different susceptibilities to infection by methicillin-resistant Staphylococcus aureus. Immunity. 2004;21(2):215-226.

23. Chan LC, et al. Innate immune memory contributes to host defense against recurrent skin and skin structure infections caused by methicillin-resistant Staphylococcus aureus. Infect Immun. 2017;85(2):e00876-16.

24. Ramírez-Valle F, Gray EE, Cyster JG. Inflammation induces dermal $\mathrm{V} \gamma 4+\gamma \delta \mathrm{T} 17$ memory-like cells that travel to distant skin and accelerate secondary IL-17-driven responses. Proc Natl Acad Sci USA. 2015;112(26):8046-8051.

25. Alegre ML, et al. Impact of Staphylococcus aureus USA300 colonization and skin infections on systemic immune responses in humans. J Immunol. 2016;197(4):1118-1126.

26. Utay NS, et al. MRSA infections in HIV-infected people are associated with decreased MRSA-specific Th1 immunity. PLoS Pathog. 2016;12(4):e1005580.

27. Zielinski CE, et al. Pathogen-induced human TH17 cells produce IFN- $\gamma$ or IL-10 and are regulated by IL-1 $\beta$. Nature. 2012;484(7395):514-518.

28. Sheridan BS, et al. $\gamma \delta$ T cells exhibit multifunctional and protective memory in intestinal tissues. Immunity. 2013;39(1):184-195.

29. Cai Y, et al. Differential developmental requirement and peripheral regulation for dermal $\mathrm{V} \gamma 4$ and $\mathrm{V} \gamma 6 \mathrm{~T} 17$ cells in health and inflammation. Nat Commun. 2014;5:3986.

30. Pantelyushin S, et al. Roryt+ innate lymphocytes and $\gamma \delta$ T cells initiate psoriasiform plaque formation in mice. J Clin Invest. 2012;122(6):2252-2256.

31. Sumaria N, et al. Cutaneous immunosurveillance by self-renewing dermal $\gamma \delta$ T cells. J Exp Med. 2011;208(3):505-518.

32. Murphy AG, O'Keeffe KM, Lalor SJ, Maher BM, Mills KH, McLoughlin RM. Staphylococcus aureus infection of mice expands a population of memory $\gamma \delta$ T cells that are protective against subsequent infection. JImmunol. 2014;192(8):3697-3708.

33. Bonneville M, O’Brien RL, Born WK. $\gamma \delta$ T cell effector functions: a blend of innate programming and acquired plasticity. Nat Rev Immunol. 2010;10(7):467-478.

34. Lalor SJ, McLoughlin RM. Memory $\gamma \delta$ T cells-newly appreciated protagonists in infection and immunity. Trends Immunol. 2016;37(10):690-702.

35. Vantourout P, Hayday A. Six-of-the-best: unique contributions of $\gamma \delta$ T cells to immunology. Nat Rev Immunol. 2013;13(2):88-100.

36. Brady RA, Bruno VM, Burns DL. RNA-seq analysis of the host response to Staphylococcus aureus skin and soft tissue infection in a mouse model. PLoS One. 2015;10(4):e0124877.

37. Holland SM. Chronic granulomatous disease. Clin Rev Allergy Immunol. 2010;38(1):3-10.

38. Chandran SS, Verhoeven D, Teijaro JR, Fenton MJ, Farber DL. TLR2 engagement on dendritic cells promotes high frequency effector and memory CD4 T cell responses. JImmunol. 2009;183(12):7832-7841.

39. Kaech SM, Tan JT, Wherry EJ, Konieczny BT, Surh CD, Ahmed R. Selective expression of the interleukin 7 receptor identifies effector CD8 T cells that give rise to long-lived memory cells. Nat Immunol. 2003;4(12):1191-1198.

40. Nielsen MM, Witherden DA, Havran WL. $\gamma \delta$ T cells in homeostasis and host defence of epithelial barrier tissues. Nat Rev Immunol. 2017;17(12):733-745.

41. Martin B, Hirota K, Cua DJ, Stockinger B, Veldhoen M. Interleukin-17-producing $\gamma \delta$ T cells selectively expand in response to pathogen products and environmental signals. Immunity. 2009;31(2):321-330.

42. Barin JG, et al. Collaborative interferon- $\gamma$ and interleukin-17 signaling protects the oral mucosa from Staphylococcus aureus. Am J Pathol. 2016;186(9):2337-2352.

43. Asarnow DM, Kuziel WA, Bonyhadi M, Tigelaar RE, Tucker PW, Allison JP. Limited diversity of gamma delta antigen receptor genes of Thy-1+ dendritic epidermal cells. Cell.1988;55(5):837-847.
44. Itohara S, et al. Homing of a gamma delta thymocyte subset with homogeneous T-cell receptors to mucosal epithelia. Nature. 1990;343(6260):754-757.

45. Muñoz-Ruiz M, Sumaria N, Pennington DJ, SilvaSantos B. Thymic determinants of $\gamma \delta$ T cell differentiation. Trends Immunol. 2017;38(5):336-344.

46. Havran WL, Chien YH, Allison JP. Recognition of self antigens by skin-derived T cells with invariant $\gamma \delta$ antigen receptors. Science. 1991;252(5011):1430-1432.

47. Komori HK, et al. Cutting edge: dendritic epidermal $\gamma \delta \mathrm{T}$ cell ligands are rapidly and locally expressed by keratinocytes following cutaneous wounding. J Immunol. 2012;188(7):2972-2976.

48. Heyborne KD, Cranfill RL, Carding SR, Born WK, O'Brien RL. Characterization of gamma delta T lymphocytes at the maternal-fetal interface. JImmunol. 1992;149(9):2872-2878.

49. Reardon C, Lefrancois L, Farr A, Kubo R, O’Brien R, Born W. Expression of gamma/delta T cell receptors on lymphocytes from the lactating mammary gland.JExp Med.1990;172(4):1263-1266.

50. Paget C, et al. CD3bright signals on $\gamma \delta$ T cells identify IL-17A-producing V $\gamma 6 \mathrm{~V} \delta 1^{+} \mathrm{T}$ cells. Immunol Cell Biol. 2015;93(2):198-212.

51. Conti HR, et al. Oral-resident natural Th17 cells and $\gamma \delta$ T cells control opportunistic Candida albicans infections. JExp Med. 2014;211(10):2075-2084.

52. Misiak A, Wilk MM, Raverdeau M, Mills KH. IL-17-producing innate and pathogen-specific tissue resident memory $\gamma \delta \mathrm{T}$ cells expand in the lungs of Bordetella pertussis-infected mice. J Immunol. 2017;198(1):363-374.

53. Okamoto Yoshida Y, et al. Essential role of IL-17A in the formation of a mycobacterial infection-induced granuloma in the lung. J Immunol. 2010;184(8):4414-4422.

54. Davey MS, et al. Clonal selection in the human V $\delta 1 \mathrm{~T}$ cell repertoire indicates $\gamma \delta$ TCR-dependent adaptive immune surveillance. Nat Commun. 2017;8:14760.

55. Dimova T, et al. Effector V $\gamma 9 \mathrm{~V} \delta 2 \mathrm{~T}$ cells dominate the human fetal $\gamma \delta$ T-cell repertoire. Proc Natl Acad Sci USA. 2015;112(6):E556-E565.

56. Papotto PH, Ribot JC, Silva-Santos B. IL-17+ $\gamma \delta$ T cells as kick-starters of inflammation. Nat Immunol. 2017;18(6):604-611.

57. Karauzum H, Haudenschild CC, Moore IN, Mahmoudieh M, Barber DL, Datta SK. Lethal CD4 $\mathrm{T}$ cell responses induced by vaccination against Staphylococcus aureus bacteremia. JInfect Dis. 2017;215(8):1231-1239.

58. Sanchez M, et al. O-acetylation of peptidoglycan limits helper $\mathrm{T}$ cell priming and permits Staphylococcus aureus reinfection. Cell Host Microbe. 2017;22(4):543-551.e4.

59. Boyden LM, et al. Skint1, the prototype of a newly identified immunoglobulin superfamily gene cluster, positively selects epidermal gammadelta T cells. Nat Genet. 2008;40(5):656-662.

60. Keyes BE, et al. Impaired epidermal to dendritic T cell signaling slows wound repair in aged skin. Cell. 2016;167(5):1323-1338.e14.

61. Marusina AI, et al. CD4+ virtual memory: Antigen-inexperienced $\mathrm{T}$ cells reside in the naive, regulatory, and memory $\mathrm{T}$ cell compartments at similar frequencies, implications for autoimmunity. J Autoimmun. 2017;77:76-88. 